\title{
Occurrence and Biosynthesis of Endogenous Cannabinoid Precursor, N-Arachidonoyl Phosphatidylethanolamine, in Rat Brain
}

\author{
Hugues Cadas, Emmanuelle di Tomaso, and Daniele Piomelli \\ The Neurosciences Institute, San Diego, California 92121
}

It has been suggested that anandamide ( $N$-arachidonoylethanolamine), an endogenous cannabinoid substance, may be produced through $\mathrm{Ca}^{2+}$-stimulated hydrolysis of the phosphatidylethanolamine (PE) derivative $\mathrm{N}$-arachidonoyl PE. The presence of $\mathrm{N}$-arachidonoyl PE in adult brain tissue and the enzyme pathways that underlie its biosynthesis are, however, still undetermined. We report here that rat brain tissue contains both anandamide (11 $\pm 7 \mathrm{pmol} / \mathrm{gm}$ wet tissue) and $N$-arachidonoyl PE (22 \pm $16 \mathrm{pmol} / \mathrm{gm})$, as assessed by gas chromatography/mass spectrometry. We describe a $\mathrm{N}$-acyltransferase activity in brain that catalyzes the biosynthesis of $N$-arachidonoyl PE by transferring an arachidonate group from the $s n-1$ carbon of phospholipids to the amino group of PE. We also show that $s n-1$ arachidonoyl phospholipids are present in brain, where they constitute $\sim 0.5 \%$ of total phospholipids. $\mathrm{N}$-acyltransferase activity is $\mathrm{Ca}^{2+}$ dependent and is enriched in brain and testis. Within the brain,
$\mathrm{N}$-acyltransferase activity is highest in brainstem; intermediate in cortex, striatum, hippocampus, medulla, and cerebellum; and lowest in thalamus, hypothalamus, and olfactory bulb. Pharmacological inhibition of $\mathrm{N}$-acyltransferase activity in primary cultures of cortical neurons prevents $\mathrm{Ca}^{2+}$-stimulated $\mathrm{N}$-arachidonoyl PE biosynthesis. Our results demonstrate, therefore, that rat brain tissue contains the complement of enzymatic activity and lipid substrates necessary for the biosynthesis of the anandamide precursor $N$-arachidonoyl PE. They also suggest that biosynthesis of $N$-arachidonoyl PE and formation of anandamide are tightly coupled processes, which may concomitantly be stimulated by elevations in intracellular $\mathrm{Ca}^{2+}$ occurring during neural activity.

Key words: anandamide; N-acylethanolamines; phosphatidylethanolamine; N-acylphosphatidylethanolamine; $\mathrm{N}$-acyltransferase; arachidonate; endogenous cannabinoids
The psychoactive effects of $\Delta^{9}$-tetrahydrocannabinol, the major pharmacological ingredient of Cannabis sativa, are produced through the activation of selective $\mathrm{G}$ protein-coupled membrane receptors (see Howlett, 1995, for review). The abundant expression of cannabinoid receptors in brain and the behavioral consequences of their activation, ranging in humans from euphoria to memory deficits, underscore the potential importance of the endogenous signaling system by which these receptors are thought to be engaged (Dewey, 1986; Hollister, 1986; Herkenham et al., 1990, 1991; Matsuda et al., 1993;). Yet, the biochemical nature, anatomical distribution, and physiological functions of such signaling systems remain elusive.

A primary candidate for the role of endogenous cannabinoid substance anandamide ( $N$-arachidonoylethanolamine) has been identified recently (Devane et al., 1992). Like $\Delta^{9}$ tetrahydrocannabinol, anandamide binds with high affinity to cannabinoid receptors, reduces contractions in mouse vas deferens, and modulates the activities of adenylyl cyclase and voltagedependent ion channels in neurons and other cells (Devane et al., 1992; Deadwyler et al., 1993, 1995; Felder et al., 1993; Vogel et al., 1993; Mackie et al., 1993; Shen et al., 1996). Moreover, anandamide elicits, in vivo, a series of behavioral responses typical of cannabinoid drugs (in rodents, hypomotility, analgesia, hypothermia, and catalepsy) (Crawley et al., 1993; Fride and Mechoulam,

Received Oct. 4, 1996; revised Nov. 18, 1996; accepted Nov. 25, 1996.

This work was supported by the Neurosciences Research Foundation, which receives major support from Sandoz Pharmaceutical Corporation. We thank Dr. M. Beltramo for discussion and Drs. N. Stella and J. Gally for critically reading this manuscript.

Correspondence should be addressed to Dr. Daniele Piomelli, The Neurosciences Institute, 10640 J. J. Hopkins Drive, San Diego, CA 92121.

Copyright (C) 1997 Society for Neuroscience $0270-6474 / 97 / 171226-17 \$ 05.00 / 0$
1993; Smith et al., 1994; Romero et al., 1995). Although the pharmacological properties of anandamide are beginning to be well understood, we still lack essential information on the biochemical mechanisms underlying the biogenesis of this signaling molecule.

Two such mechanisms have been proposed. Anandamide may be synthesized through the energy-independent condensation of ethanolamine and arachidonate (Deutsch and Chin, 1993; Devane and Axelrod, 1994; Kruszka and Gross, 1994). This reaction, however, requires $\mathrm{pH}$ optima and substrate concentrations that are unlikely to be found in neurons. Also, various lines of evidence indicate that condensation of ethanolamine and arachidonate may result from the reverse reaction of "anandamide amidohydrolase," an enzyme activity involved in anandamide breakdown (Schmid et al., 1985; Desarnaud et al., 1995; Ueda et al., 1995).

An additional mechanism of anandamide formation, suggested by experiments carried out in cultures of rat brain neurons, is via the phosphodiesterase-mediated cleavage of a phospholipid precursor, $N$-arachidonoyl phosphatidylethanolamine (PE) (Di Marzo et al., 1994; Cadas et al., 1996a). For this mechanism to be considered plausible, two necessary conditions should be fulfilled. First, the occurrence of $N$-arachidonoyl PE in adult brain tissue should be demonstrated. Second, the enzyme pathway(s) that is responsible for the biosynthesis of $N$-arachidonoyl PE should be identified. Studies carried out in the laboratory of Schmid et al. before the discovery of anandamide have reported the occurrence in brain of an $N$-acyltransferase activity, which catalyzes the formation of other $N$-acyl PEs by transferring a saturated or monounsaturated fatty acyl group from the $s n-1$ ester bond of phospholipids to the primary amino group of PE (Schmid et al., 1990; Schmid et al., 1996a). Is this activity implicated in the biosynthesis 
of $N$-arachidonoyl PE? Such a possibility has been raised. Arguing against it, though, is the currently accepted notion that tissue phospholipids contain no arachidonate at the $s n-1$ position, but rather saturated or monounsaturated fatty acids such as palmitate, stearate, or oleate (Shetty et al., 1996).

In the present study, we have examined the occurrence and biosynthesis of $N$-arachidonoyl PE in adult rat brain tissue. Using highly sensitive and selective gas chromatography/mass spectrometry (GC/ MS) techniques, we show that $N$-arachidonoyl PE and anandamide are constituents of brain lipids. Further, we identify and partially characterize an $\mathrm{N}$-acyltransferase activity in brain that catalyzes the biosynthesis of $N$-arachidonoyl $\mathrm{PE}$, using as substrates $s n$-1 arachidonoyl-phospholipids and PE. Even further, we describe a novel brain phospholipid that contains arachidonate at the $s n-1$ position, and may therefore serve as substrate for such enzyme activity. Finally, we show that stimulation of $N$-acyltransferase activity satisfactorily accounts for the $\mathrm{Ca}^{2+}$-evoked biosynthesis of $N$-arachidonoyl PE observed in intact neurons. During the preparation of this manuscript, results very similar to ours were reported in a study by Sugiura et al. (1996b).

\section{MATERIALS AND METHODS}

Materials. $1,2-\mathrm{Di}\left[1-{ }^{14} \mathrm{C}\right]$ arachidonoyl phosphatidylcholine (PC; $110 \mathrm{mCi} /$ mmol; custom synthesized), 1-palmitoyl,2-[1- $\left.{ }^{14} \mathrm{C}\right]$ arachidonoyl phosphatidylethanolamine (PE; $54 \mathrm{mCi} / \mathrm{mmol})$, and $\left[1-{ }^{3} \mathrm{H}\right]$ ethanolamine hydrochloride $(50 \mathrm{Ci} / \mathrm{mmol})$ were from American Radiolabeled Chemicals (St. Louis, MO). 1,2-di[ $\left[1{ }^{14} \mathrm{C}\right]$ palmitoyl PC $(112 \mathrm{mCi} / \mathrm{mmol})$, 1-stearoyl,2-[1$\left.{ }^{14} \mathrm{C}\right]$ palmitoyl PC $(56 \mathrm{mCi} / \mathrm{mmol})$, and 1 -stearoyl,2-[1- $\left.{ }^{14} \mathrm{C}\right]$ arachidonoyl PC $(54 \mathrm{mCi} / \mathrm{mmol})$ were from Amersham (Arlington Heights, IL). Bis(trimethylsilyl)trifluoroacetamide (BSTFA) was from Supelco (Bellefonte, PA) Phospholipase D (PLD type IV, Streptomyces chromofuscus), phospholipase $\mathrm{C}$ (PLC type IV, Bacillus cereus), and phospholipase $\mathrm{A}_{2}\left(\mathrm{PLA}_{2}\right.$, Apis mellifera) were from Sigma (St. Louis, MO). (E)-6-(bromomethylene)-tetrahydro3-(1-naphthalenyl)-2H-pyran-2-one (BTNP) was from Biomol (Plymouth Meeting, PA). Phospholipids were from Avanti Polar Lipids (Alabaster, $\mathrm{AL}$ ), monoacylglycerols and fatty acyl chlorides from Nu-Check Prep (Elysian, MN), and ionomycin from Calbiochem (San Diego, CA). All other chemicals were from Sigma (St. Louis, MO) or Fluka (Ronkonkoma, NY).

Synthesis and purification of $\mathrm{N}$-acylethanolamines. $N$-acylethanolamines (NAEs) were synthesized as described previously (Devane et al., 1992). Briefly, $300 \mu \mathrm{mol}$ ethanolamine was allowed to react with the appropriate $30 \mu \mathrm{mol}$ fatty acyl chloride in $4 \mathrm{ml}$ dichloromethane at $0-4^{\circ} \mathrm{C}$, and the reaction was stopped after $15 \mathrm{~min}$ by extracting excess ethanolamine with $15 \mathrm{ml}$ water. The NAEs were purified by column chromatography, and purity was determined by TLC and by GC/MS.

Preparation of rat tissue subcellular fractions. Male Wistar rats (Charles River, Wilmington, MA) were anesthetized with carbon dioxide and sacrificed by decapitation. Brains and other tissues were homogenized in $50 \mathrm{~mm}$ Tris buffer, $\mathrm{pH} 8$, containing $0.32 \mathrm{~m}$ sucrose. Tissue extracts were centrifuged sequentially at $1000 \times g(1 \mathrm{~min}), 22,000 \times g(30 \mathrm{~min})$, and $105,000 \times g(60 \mathrm{~min})$. The pellets obtained after the second and third centrifugations were solubilized for $1 \mathrm{hr}$ at $0-4^{\circ} \mathrm{C}$ in Tris buffer containing $0.5 \% \mathrm{NP}-40$, and centrifuged again at $105,000 \times g(60 \mathrm{~min})$. In some experiments, individual brain regions were dissected and homogenized in the same buffer. The homogenates were centrifuged at 22,000 $\times g(30$ $\min$ ), and subcellular fractions were prepared as described above. All tissue samples were stored in liquid nitrogen until used.

Cell cultures. Primary cultures of cortical neurons were prepared from 18-d-old rat embryos, maintained in serum-supplemented culture medium (Huettner and Baughman, 1986) and used after 5-6 d in vitro. Neurons $\left(90 \mathrm{~mm}\right.$ dishes, plated at a density of $2.5 \times 10^{7} \mathrm{cells} /$ dish $)$ were labeled by incubation $(16-20 \mathrm{hr})$ with $\left[{ }^{3} \mathrm{H}\right]$ ethanolamine $(1 \mu \mathrm{Ci} / \mathrm{ml}, 50$ $\mu \mathrm{Ci} / \mathrm{mmol}$ ). The cultures were rinsed with DMEM (Gibco, Grand Island, $\mathrm{NY}$ ) and incubated for $10 \mathrm{~min}$ in $5 \mathrm{ml}$ DMEM containing drugs at the indicated concentrations. In experiments with BTNP, the cultures were also preincubated for $10 \mathrm{~min}$ with the drug. Incubations were stopped by adding $2 \mathrm{ml}$ ice-cold methanol, followed by lipid extraction.

Extraction of N-acyl PEs and NAEs. Rats were sacrificed by decapitation, and the heads were immediately $(\leq 2 \mathrm{sec})$ immersed in liquid nitrogen. After $10 \mathrm{sec}$, the heads were removed, and the whole brains were dissected while frozen and homogenized in $20 \mathrm{ml}$ of an ice-cold sucrose-containing Tris buffer $(50 \mathrm{~mm}, \mathrm{pH} 8)$, or in a mixture of methanol/Tris buffer (1:1, $20 \mathrm{ml})$. Comparable results were obtained with either method. Lipids were extracted twice in a mixture containing chloroform, methanol, and buffer, adjusted to a volume ratio of 2:1:1. Before extraction, synthetic $N$-myristoylethanolamine $(800 \mathrm{pmol})$ was added to the mixture as an internal standard. In initial experiments, we found that $N$-myristoylethanolamine was not detectable in rat brain tissue.

Phospholipid extraction. Phospholipids were extracted according to Folch et al. (1957). Briefly, the brains were homogenized in chloroform/ methanol (2:1) and incubated on ice for $30 \mathrm{~min}$. Phase separation was achieved by adding 0.2 volumes of a solution of $\mathrm{NaCl}$ in water $(0.9 \%$, $\mathrm{w} / \mathrm{v})$. The organic phases were dried under nitrogen, reconstituted in chloroform, and loaded onto silica gel G columns. After fatty acids and neutral lipids were eluted with chloroform/methanol (9:1), the phospholipids were eluted with methanol.

Enzymatic digestions. Lipid fractions containing the $\mathrm{N}$-acyl PEs were reconstituted in ethylether and incubated in $40 \mathrm{~mm}$ MOPS buffer, $\mathrm{pH} 5.7$, containing $250 \mathrm{U} / \mathrm{ml}$ Streptomyces chromofuscus PLD and $15 \mathrm{~mm} \mathrm{CaCl}$. Incubations were carried out for $2 \mathrm{hr}$ at $37^{\circ} \mathrm{C}$ with shaking. The reaction products were extracted with chloroform/methanol (2:1) and fractionated by column chromatography. Purified brain phospholipids were subjected to sequential enzymatic digestions. They were first digested for $2 \mathrm{hr}$ at $37^{\circ} \mathrm{C}$ with $50 \mathrm{U} / \mathrm{ml}$ Apis mellifera $\mathrm{PLA}_{2}$ in $100 \mathrm{~mm}$ Tris buffer, pH 9, containing 10 $\mathrm{mM} \mathrm{CaCl}_{2}$. The reaction mixtures were acidified with Tris buffer, $\mathrm{pH} \mathrm{4}$, and extracted with chloroform/methanol. The lysophospholipids produced during these reactions were further digested for $2 \mathrm{hr}$ with $80 \mathrm{U} / \mathrm{ml}$ Bacillus cereus PLC in $200 \mathrm{~mm}$ phosphate buffer, $\mathrm{pH} 7$, containing $0.4 \mathrm{~mm}$ ) $\mathrm{ZnCl}_{2}$ and $1 \mathrm{~mm}$ ) $\beta$-mercaptoethanol. Sphingomyelin $(0.5 \mathrm{mg} / \mathrm{ml})$ was added to these incubations to enhance PLC activity (Wood and Snyder, 1969). The specificity of all enzymatic digestions were verified in initial experiments by using synthetic standards (data not shown). Synthetic 800 pmol sn-1 eicosanoylglycerol was included as internal standard, and the monoacylglycerols were extracted with chloroform/methanol.

Lipid purification and analysis. Brain lipid extracts were subjected to chromatography on silica gel G columns. NAEs and monoacylglycerols were eluted with chloroform/methanol (9:1), and $N$-acyl PEs with chloroform/methanol (6:4). In some experiments, the $N$-acyl PE fractions were analyzed by monodimensional TLC, using a solvent system of chloroform/methanol/ammonium hydroxide (80:20:1). Lipids were visualized by spraying the TLC plates with a solution of phosphomolybdic acid in ethanol $(10 \%, \mathrm{w} / \mathrm{v})$ and heating at $150^{\circ} \mathrm{C}$ for $5 \mathrm{~min}$. Plastic-backed TLC plates were cut into $1 \mathrm{~cm}$ bands, and radioactivity in the bands was measured by liquid scintillation counting. In other experiments, $N$-acyl PEs were analyzed by bidimensional high-performance TLC (HPTLC, system 1: chloroform/methanol/ammonium hydroxide, 80:20:1; system 2: chloroform/methanol/acetic acid, 80:20:1), visualized by autoradiography using a Phosphor-Imager 445 SI apparatus (Molecular Dynamics, Sunnyvale, CA), and identified by comigration with an authentic standard. Yet in other experiments, $N$-acyl PEs were analyzed by reversed-phase HPLC with the use of a $\mu$ Bondapak $\mathrm{C}_{18}$ column $(3.9 \mathrm{~mm} \times 30 \mathrm{~cm}$, Waters Associates) eluted with a gradient of water in methanol (from 30 to $0 \%$ over $10 \mathrm{~min}$ ) at a flow rate of $1.5 \mathrm{ml} / \mathrm{min}$. NAEs were purified after column chromatography by normal-phase HPLC with the use of a Resolve silica column $(3.9 \mathrm{~mm} \times 15 \mathrm{~cm}, 5 \mu \mathrm{m}$, Waters Associates) eluted with a gradient of 2-propanol in $n$-hexane (from 0 to $20 \%$ over $20 \mathrm{~min}$ ) at a flow rate of $1.5 \mathrm{ml} / \mathrm{min}$. NAEs were eluted from the HPLC at $12-13 \mathrm{~min}$ and collected in glass reaction vessels (Supelco, Bellefonte, PA) for chemical derivatization. NAEs and monoacylglycerols were derivatized by treatment with BSTFA (15-30 min at room temperature), dried under nitrogen, and resuspended in $n$-hexane. The trimethylsilylether (TMS) derivatives were injected in the splitless mode into a Hewlett-Packard $5890 \mathrm{GC}$ equipped with an HP-5MS capillary column $(30 \mathrm{~m}$; internal diameter, $0.25 \mathrm{~mm}$ ), and interfaced with a Hewlett-Packard 5972 MS. One minute after the injection, the oven temperature was increased from $150^{\circ} \mathrm{C}$ to $280^{\circ} \mathrm{C}$ at a rate of $8^{\circ} \mathrm{C} / \mathrm{min}$. The injector temperature was kept at $250^{\circ} \mathrm{C}$, and helium was used as carrier gas. To improve recovery of the NAEs, and to allow for their quantitative analysis, we included $800 \mathrm{pmol}$ synthetic $N$-myristoylethanolamine in all samples as an internal standard. The TMS derivative of $N$-myristoylethanolamine was eluted from the GC at a retention time of $\sim 13.5 \mathrm{~min}$, and its electron impact mass spectrum displayed a series of informative ions which included: $\mathrm{m} / \mathrm{z} 343\left(\mathrm{M}^{+}\right.$, molecular ion); m/z 328 (M-15, loss of a methyl group); m/z 300 (M-43, loss of a propyl group); m/z 253 (M-90, loss of [HO-TMS] ${ }^{+}$); and m/z 175 (McLafferty rearrangement). For selected ion monitoring (SIM) analyses, we chose the fragment at $\mathrm{m} / \mathrm{z} 328$ (M-15). With this ion, the MS response 
was linear $\left(r_{2}=0.98\right)$ when amounts of $N$-myristoylethanolamine-TMS ranging between 0.2 and 400 pmol were injected into the GC.

$\mathrm{N}$-acyltransferase assay. Standard $\mathrm{N}$-acyltransferase assays were carried out for $1 \mathrm{hr}$ at $37^{\circ} \mathrm{C}$ in $0.5 \mathrm{ml}$ of Tris buffer $(50 \mathrm{~mm}, \mathrm{pH} 8)$, to which we added $0.3 \mathrm{mg}$ protein, $3 \mathrm{~mm} \mathrm{CaCl}$, and $1 \times 10^{6} \mathrm{dpm}$ radioactive substrates. Parallel incubations carried out in the absence of tissue contained on average $100 \mathrm{dpm} / \mathrm{sample}$; these blank values were subtracted in the calculations of enzyme activity. Incubations were stopped by adding chloroform/methanol (2:1), and the $N$-acyl PEs were fractionated by column chromatography. In some experiments, to verify that all the radioactive material eluting in the $N$-acyl PE fractions comigrated with authentic $N$-acyl PE, samples were analyzed by TLC or HPTLC.

Identification of $\mathrm{N}$-acyltransferase by fast protein liquid chromatography (FPLC). Crude brain particulate fractions containing $N$-acyltransferase activity were solubilized and analyzed by FPLC (Pharmacia, Piscataway) using a MonoQ column (HR 10/10). The column was equilibrated at 2 $\mathrm{ml} / \mathrm{min}$ with $20 \mathrm{~mm}$ Tris buffer, $\mathrm{pH} 8.1$, containing $0.05 \% \mathrm{NP}-40$ and $3 \mathrm{~mm}$ $\mathrm{CaCl}_{2}$. Proteins were eluted with a gradient of $\mathrm{NaCl}$ (from $50 \mathrm{~mm}$ to $1 \mathrm{M}$ ). $\mathrm{N}$-acyltransferase activity was measured in samples of the eluted fractions under standard conditions. The assay mixtures contained 1,2di $\left[{ }^{14}\right.$ C]palmitoyl PC, $32 \mu \mathrm{g} / \mathrm{ml}$ PC, $42 \mu \mathrm{g} / \mathrm{ml} \mathrm{PE}$, and $26 \mu \mathrm{g} / \mathrm{ml}$ phosphatidylserine.

\section{RESULTS}

\section{$\boldsymbol{N}$-Arachidonoyl PE and other $\boldsymbol{N}$-acyl PEs are normal constituents of rat brain lipids}

The levels of $N$-acyl PEs in brain tissue increase dramatically as a result of hypoxic insults (Natarajan et al., 1981). This circumstance suggests that these lipids may be generated exclusively during cerebral ischemia and, as such, may not participate in normal brain function (Schmid et al., 1990). We examined, therefore, whether $N$-acyl PEs, and particularly $N$-arachidonoyl PE, were present in rat brain tissue in which metabolic changes associated with ischemic damage had been prevented by immersing the head of the animal in liquid nitrogen within $2 \mathrm{sec}$ of decapitation (Aveldano de Caldironi and Bazan, 1979; DeMedio et al., 1980; Tang and Sun, 1985). We extracted total brain lipids in methanol/chloroform, fractionated the extracts by column chromatography, and analyzed them by bidimensional HPTLC. The results of these analyses, illustrated in Figure $1 A$, indicated that a lipid component with the chromatographic properties of $N$-acyl PEs is present in the extracts.

To confirm this identification and to determine the molecular composition of brain $N$-acyl PEs, in six additional experiments we digested the lipid fractions containing $N$-acyl PEs with a bacterial PLD (Schmid et al., 1990). Under appropriate conditions, this enzyme quantitatively hydrolyzes the distal phosphodiester bond of $N$-acyl PEs, releasing the corresponding NAEs (a scheme of this reaction is depicted in Fig. $1 B$ ). The NAEs produced in these digestions were then purified by a combination of column chromatography and normal-phase HPLC, and analyzed by GC/MS as TMS derivatives. The electron-impact mass spectra of the TMS derivatives of synthetic anandamide and other NAEs are shown in Figure 2. From these mass spectra we chose characteristic ions for analysis by SIM, a technique that provides both high sensitivity and specificity of detection. We observed diagnostic fragments for anandamide $\left(\mathrm{m} / \mathrm{z} 419, \mathrm{M}^{+} ; \mathrm{m} / \mathrm{z}\right.$ 404, M-15; m/z 328, M-91), $N$-palmitoylethanolamine (m/z 356, M-15), $N$-stearoylethanolamine (m/z 384, M-15), and $N$-oleoylethanolamine $(\mathrm{m} / \mathrm{z} 382$, $\mathrm{M}-15$ ), which were eluted from the $\mathrm{GC}$ at the retention times expected for these compounds (Fig. 3 and data not shown).

These results indicate that a family of $N$-acyl PEs, including $N$-arachidonoyl PE, are normal constituents of rat brain lipids. By comparison with an internal standard, we estimated that an average of $22 \pm 16 \mathrm{pmol}$ of $N$-arachidonoyl PE were recovered from $1 \mathrm{gm}$ of wet brain tissue after lipid extraction and purification. The

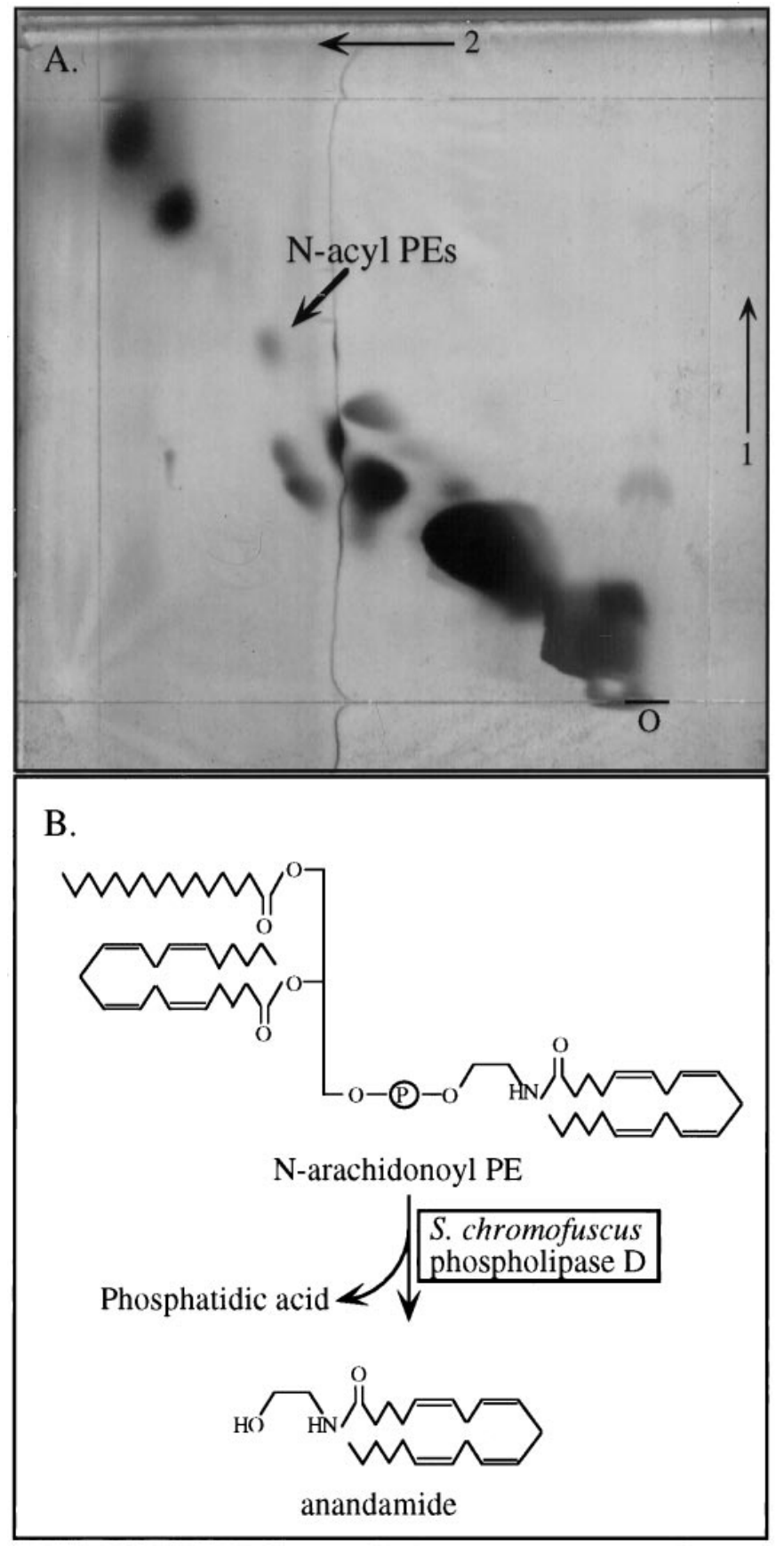

Figure 1. A, Identification of brain $N$-acyl PEs by bidimensional HPTLC Phosphomolybdic acid staining revealed the presence of a lipid component, indicated by the arrow, with the chromatographic properties of $N$-acyl PEs. Results are from one experiment, repeated once with identical results. $B$, Analytical approach used to confirm the identification of brain $N$-acyl PEs and to determine their molecular composition. Partially purified $N$-acyl PEs were digested with $S$. chromofuscus PLD to release the corresponding NAEs. These were subsequently purified by HPLC and analyzed by GC/MS.

percent composition of brain $N$-acyl PEs determined in these experiments is illustrated in Table 1.

\section{Anandamide and other NAEs are also present in brain tissue}

We next examined whether rapidly frozen brain tissue contains anandamide and other NAEs. We purified the NAEs by column 
A.

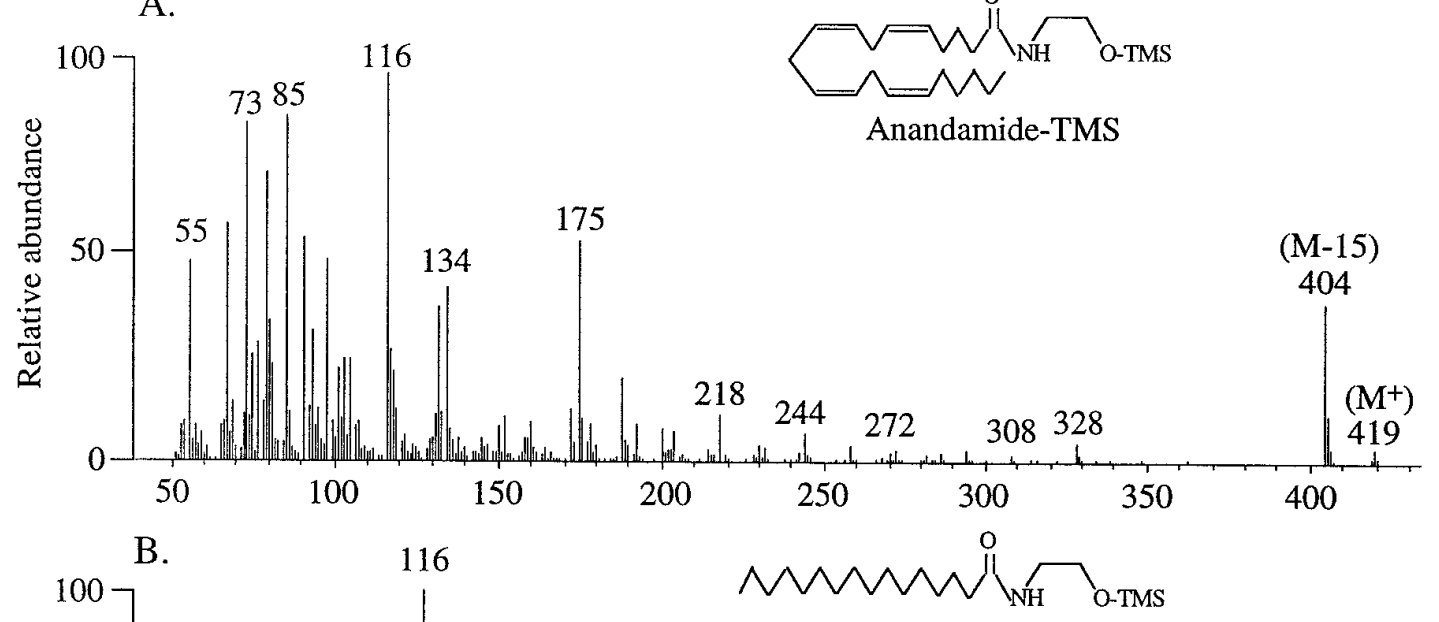

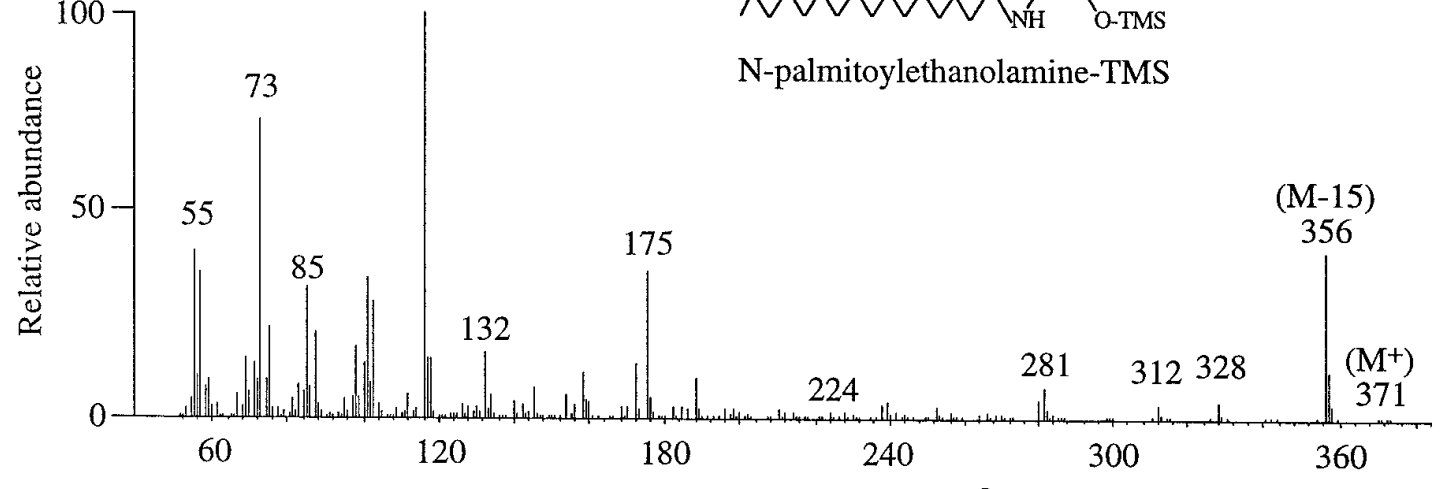
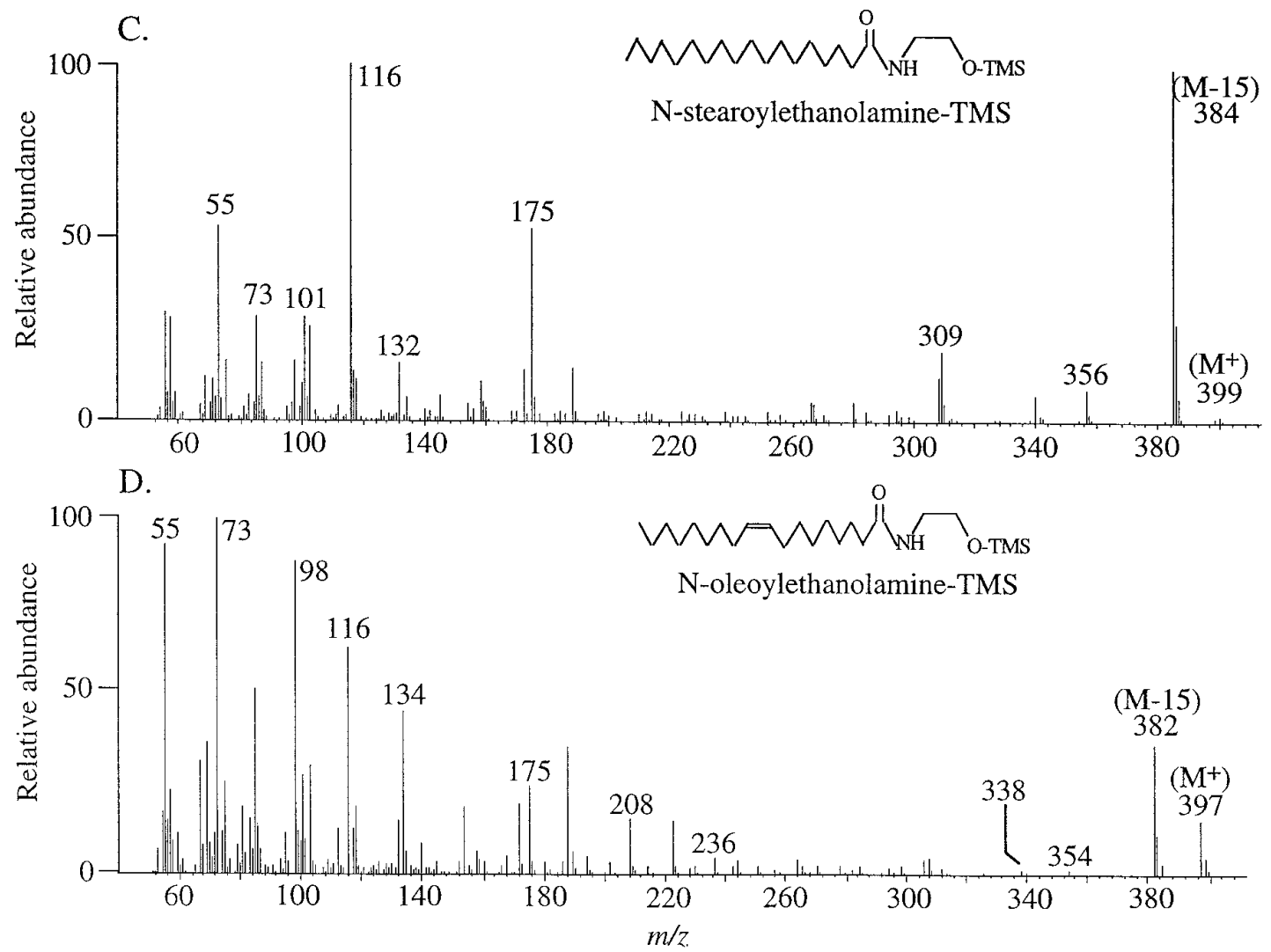

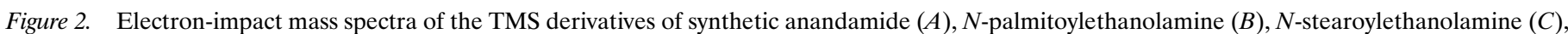
and $N$-oleoylethanolamine $(D)$. 
Figure 3. Identification of $\mathrm{N}$-arachidonoyl PE and other $N$-acyl PEs in brain by $\mathrm{GC} / \mathrm{MS}$. $N$-acyl PEs were digested with $S$. chromofuscus PLD, and the resulting NAEs were analyzed by GC/MS in the SIM mode as TMS derivatives. $A$, Anandamide, derived from the hydrolysis of $N$-arachidonoyl PE; $B$, NAEs derived from the hydrolysis of $N$-palmitoyl PE, $N$-stearoyl PE, and $N$-oleoyl PE. The arrows indicate the retention times of authentic standards. Results are from one experiment, representative of six.
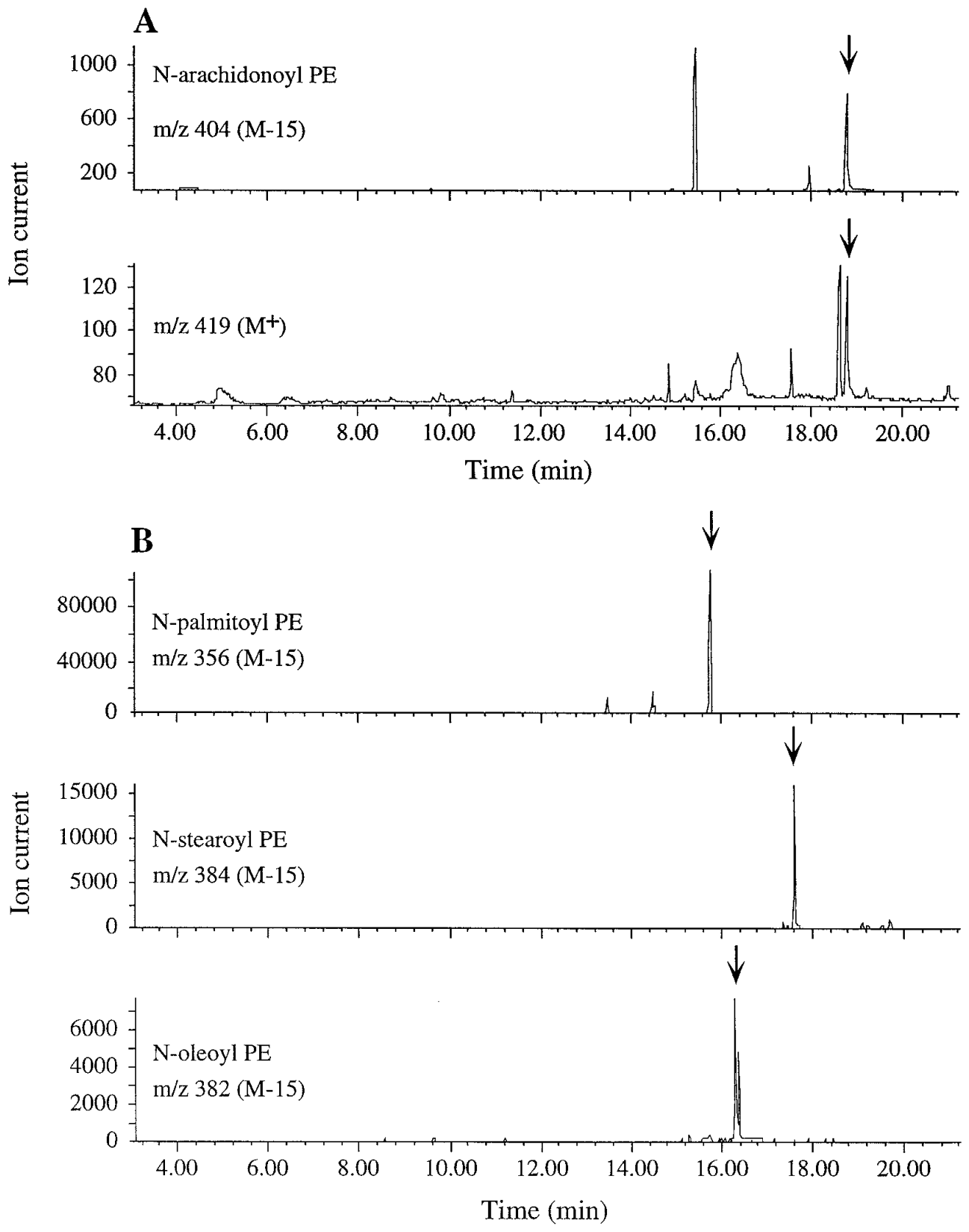

\section{Table 1. Molecular composition of rat brain $N$-acyl PEs}

\begin{tabular}{ll}
$N$-acyl PE & $\begin{array}{l}\text { Amount } \\
(\% \text { total } \pm \mathrm{SEM})\end{array}$ \\
\hline$N$-palmitoyl & $83.9 \pm 1$ \\
$N$-stearoyl & $10.6 \pm 1$ \\
$N$-oleoyl & $4.8 \pm 0.3$ \\
$N$-arachidonoyl & $0.6 \pm 0.1$
\end{tabular}

Analyses of rat brain $N$-acyl PEs were carried out as described in Materials and Methods. Results are expressed as percent of total $N$-acyl PEs present, and represent the mean \pm SEM of six experiments.

chromatography and normal-phase HPLC, and analyzed them by GC/MS. In six experiments, a component of the HPLC-purified brain extract was eluted at a retention time of $18.7 \mathrm{~min}$, identical to that of synthetic anandamide (Fig. 4). Diagnostic ions were detected at $\mathrm{m} / \mathrm{z} 419, \mathrm{~m} / \mathrm{z} 404$, and $\mathrm{m} / \mathrm{z} 328$ (Fig. $4 A$ and data not shown). We also observed ions typical of three additional NAEs (Fig. $4 B$; compare with the mass spectra of synthetic NAEs shown in Fig. 2, $B-D)$. In these experiments, we measured an average of $11 \pm 7 \mathrm{pmol}$ of anandamide/gm wet tissue, accounting for $\sim 8 \%$ of the total NAEs detected (Table 2).

\section{Enzymatic biosynthesis of $\boldsymbol{N}$-arachidonoyl PE}

We have shown that small amounts of the putative anandamide precursor, $N$-arachidonoyl $\mathrm{PE}$, are present in brain tissue. To explore the physiological roles of this lipid, it was first essential to characterize the biochemical mechanisms responsible for its biosynthesis. We examined, therefore, whether $N$-arachidonoyl PE may be produced de novo in brain subcellular fractions. We solubilized crude particulate fractions and incubated them for 60 min with or without $3 \mathrm{mM} \mathrm{CaCl}_{2}$. When we analyzed the lipid extracts of $\mathrm{Ca}^{2+}$-containing incubations, we noted a lipid component that comigrated with $N$-acyl PEs on HPTLC (Fig. 5A). In contrast, this component was not detectable in $\mathrm{Ca}^{2+}$-free incuba- 

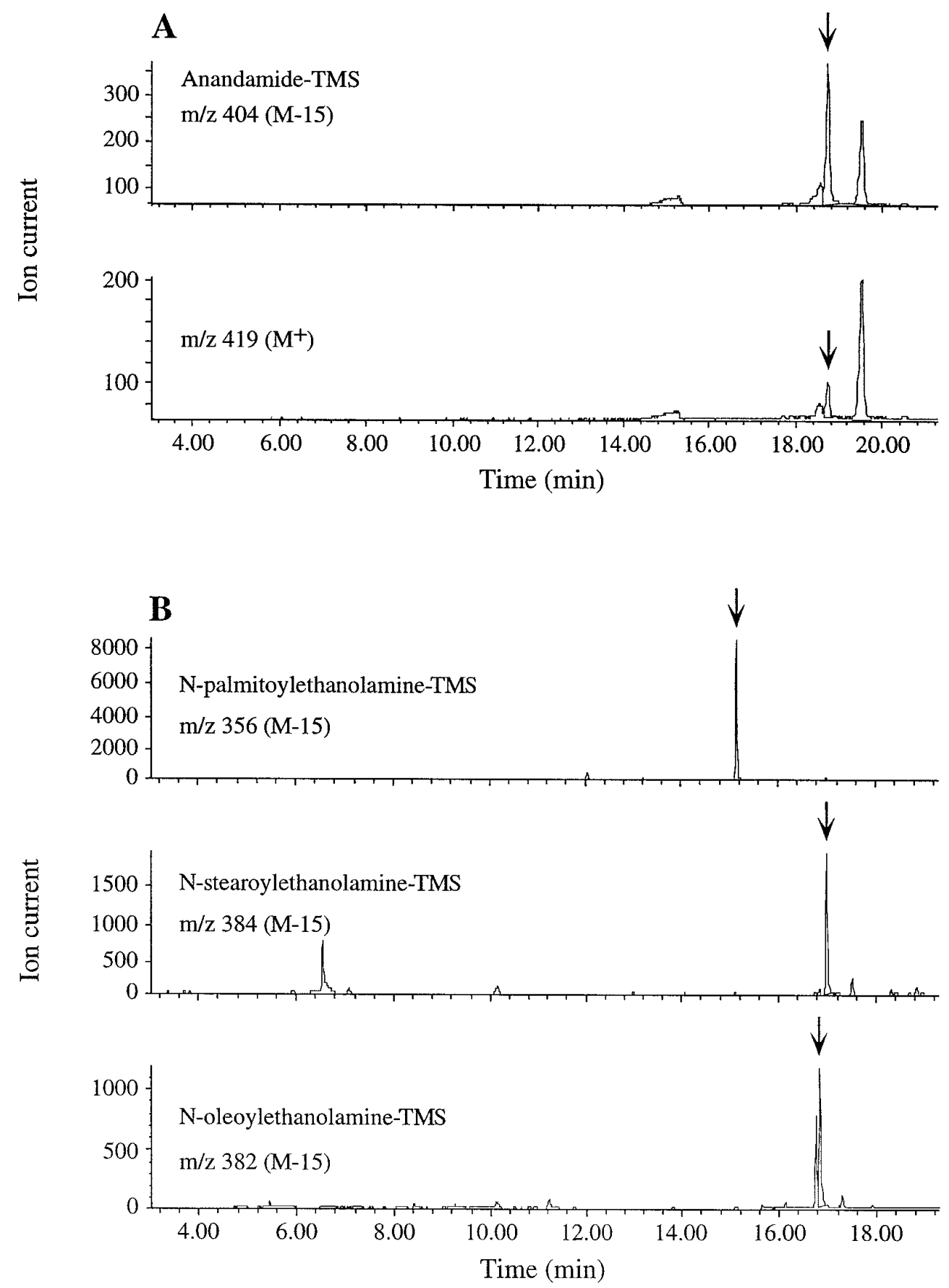

Figure 4. Identification of anandamide and other NAEs in brain by GC/MS. The NAEs were purified chromatographically and analyzed by GC/MS in the SIM mode as TMS derivatives. $A$, Anandamide; $B$, additional NAEs. The arrows indicate the retention times of authentic standards. Results are from one experiment, representative of six.

Table 2. Molecular composition of rat brain $N$-acylethanolamines

\begin{tabular}{lc} 
NAE & $\begin{array}{l}\text { Amount } \\
(\% \text { total } \pm \text { SEM })\end{array}$ \\
\hline$N$-palmitoyl & $65.5 \pm 6$ \\
$N$-stearoyl & $19.7 \pm 4$ \\
$N$-oleoyl & $7.6 \pm 5$ \\
Anandamide & $8.1 \pm 5$
\end{tabular}

Analyses of rat brain NAEs were carried out as described in Materials and Methods Results are expressed as percent of total NAEs present, and represent the mean \pm SEM of six experiments. tions (Fig. $5 B$ ) or in incubations of heat-inactivated fractions (data not shown). These results are in agreement with studies by Schmid et al. (1990) indicating the occurrence, in brain tissue, of a $\mathrm{Ca}^{2+}$-activated enzymatic activity that catalyzes the biosynthesis of $N$-acyl PEs.

Was $N$-arachidonoyl PE also produced in these incubations? To address this question, we partially purified the $N$-acyl PEs; digested them with bacterial PLD; and analyzed, by GC/MS, the NAEs produced. In seven experiments, we found components that eluted from the GC at the retention times of anandamide, $N$-palmitoylethanolamine, $N$-stearoylethanolamine, and $N$-oleoyl- 
A Calcium $(3 \mathrm{mM})$

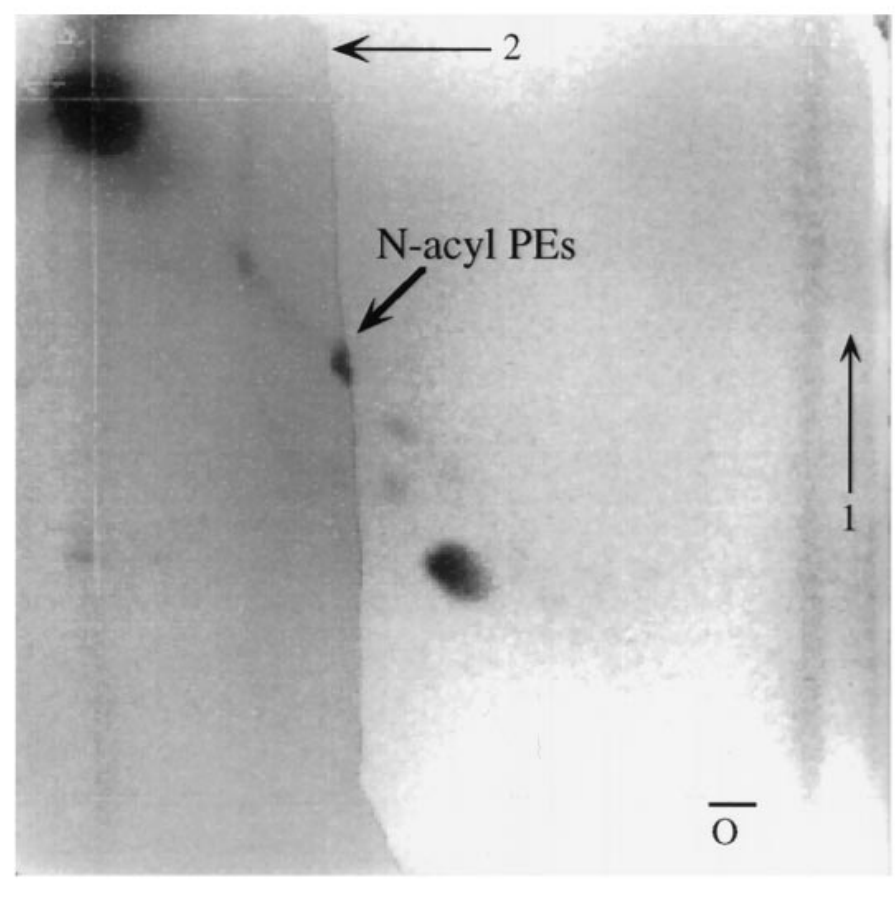

B Control

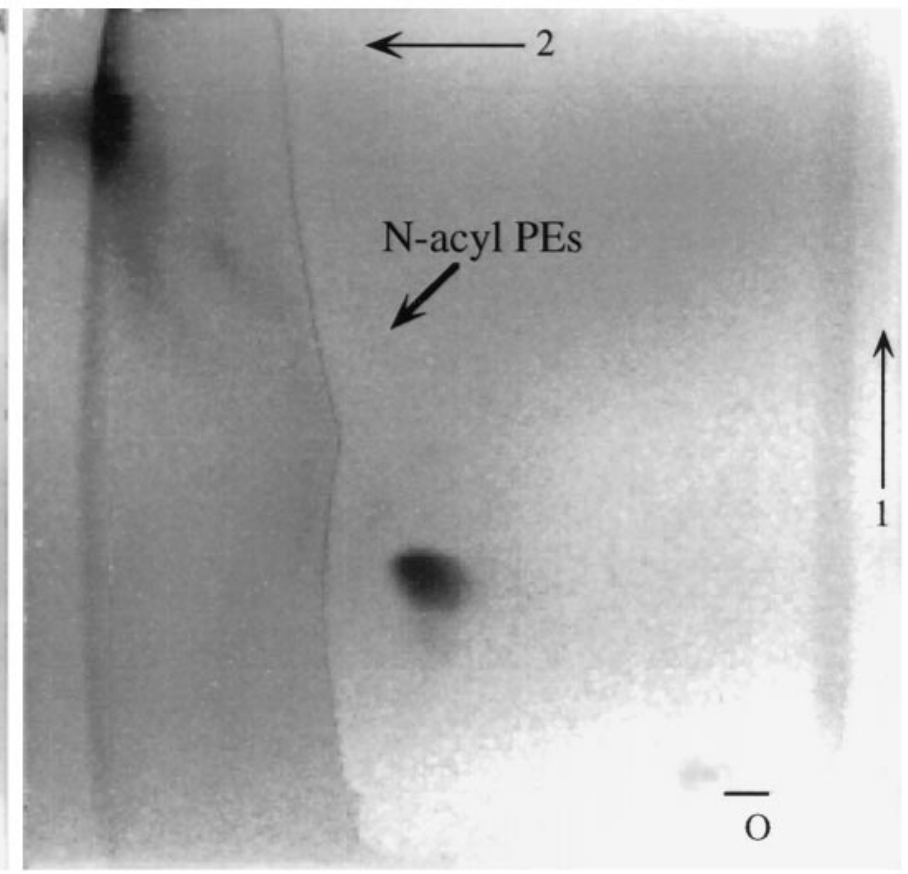

Figure 5. Brain particulate fractions contain an enzymatic activity that catalyzes the biosynthesis of $N$-acyl PEs. Particulate fractions were solubilized with the nonionic detergent, NP-40, and incubated either with $3 \mathrm{mM} \mathrm{Ca}^{2+}(A)$ or without $\mathrm{Ca}^{2+}(B)$. The lipids were analyzed by HPTLC and visualized with phosphomolybdic acid. A lipid component with the chromatographic properties of synthetic $N$-acyl PEs, indicated by the arrow, was present only in the $\mathrm{Ca}^{2+}$-containing incubations. Results are from one experiment, representative of four.

Table 3. Molecular composition of $N$-acyl PEs produced in rat brain particulate fraction

\begin{tabular}{lc}
$N$-acyl PE & $\begin{array}{l}\text { Amount } \\
\text { (\% total } \pm \mathrm{SEM} \text { ) }\end{array}$ \\
\hline$N$-palmitoyl & $43.7 \pm 1.5$ \\
$N$-stearoyl & $46.1 \pm 1.7$ \\
$N$-oleoyl & $9.4 \pm 0.6$ \\
$N$-arachidonoyl & $0.1 \pm 0.02$
\end{tabular}

Analyses of the $N$-acyl PEs produced in particulate fractions were carried out as described in Materials and Methods. Results are expressed as percent of total $N$-acyl PEs produced, and represent the mean \pm SEM of seven experiments.

ethanolamine. Because the NAEs were present in relatively high amounts $(>100 \mathrm{pmol} / \mathrm{sample})$, we were able to collect complete mass spectra for each of them (Fig. 6). Comparison of these mass spectra with those of synthetic NAEs (shown in Fig. 1) unambiguously confirmed the identification of these compounds.

Consequently, our results demonstrate that brain particulate fractions incubated in the presence of $\mathrm{Ca}^{2+}$ produce a family of $N$-acyl PEs, which include $N$-arachidonoyl PE. A quantitative account of these findings is presented in Table 3. In addition to $N$-acyl PEs, the four NAEs identified in brain tissue (anandamide, $N$-palmitoylethanolamine, $N$-stearoylethanolamine, and $N$-oleoylethanolamine) were also generated in these incubations, as determined by GC/MS analysis (data not shown).

\section{An $\mathbf{N}$-acyltransferase activity catalyzes the biosynthesis of $\mathbf{N}$-arachidonoyl PE and other N-acyl PEs}

Previous studies with various preparations of neural tissue have suggested that $N$-acyl $\mathrm{PE}$ biosynthesis is mediated by an
$N$-acyltransferase activity, which transfers a fatty acyl group from the $s n-1$ position of phospholipids to the amino group of PE (Natarajan et al., 1986; Cadas et al., 1996a). To determine whether rat brain tissue contains such activity, we incubated detergent-solubilized particulate fractions in a reaction mixture containing $\mathrm{CaCl}_{2}$ and 1,2-di $\left[{ }^{14} \mathrm{C}\right]$ palmitoyl $\mathrm{PC}$, and identified the radioactive products by HPTLC or reversed-phase HPLC. By either method, we found a major radioactive component that displayed the chromatographic properties of $N$-acyl PEs, indicating the formation of $N-\left[{ }^{14} \mathrm{C}\right]$ palmitoyl PE (Fig. 7A, $C$ ). In contrast, parallel incubations carried out in the absence of $\mathrm{Ca}^{2+}$ or with heat-inactivated samples contained no detectable $N$ - $\left[{ }^{14} \mathrm{C}\right]$ palmitoyl PE (Fig. 5B,D and data not shown). Likewise, we found no $N$ - $\left[{ }^{14} \mathrm{C}\right]$ palmitoyl PE when we used 1-stearoyl,2$\left[{ }^{14} \mathrm{C}\right]$ palmitoyl PC as fatty acyl donor (Table 4). Analysis of additional subcellular fractions of rat brain tissue showed that $N$-acyltransferase activity is present both in crude particulate fractions and in microsomes, and is enriched in the former (Table 4). To characterize $N$-acyltransferase activity further, in three subsequent experiments we applied solubilized particulate fractions to a MonoQ FPLC column and measured the enzyme activity in the eluate. Using an assay buffer that contained 1,2-di[ ${ }^{14} \mathrm{C}$ ]palmitoyl $\mathrm{PC}$, exogenous $\mathrm{PE}$, and $\mathrm{CaCl}_{2}$, we detected one major peak of enzyme activity in association with a UV-absorbing component (Fig. 8). Thus, our results confirm that rat brain tissue contains a $N$-acyltransferase activity that catalyzes the biosynthesis of saturated and monounsaturated $N$-acyl PEs.

We considered that the biosynthesis of $N$-arachidonoyl PE may proceed through a similar mechanism. To address this possibility, it was first necessary to show that, in brain tissue, an arachidonoyl- 

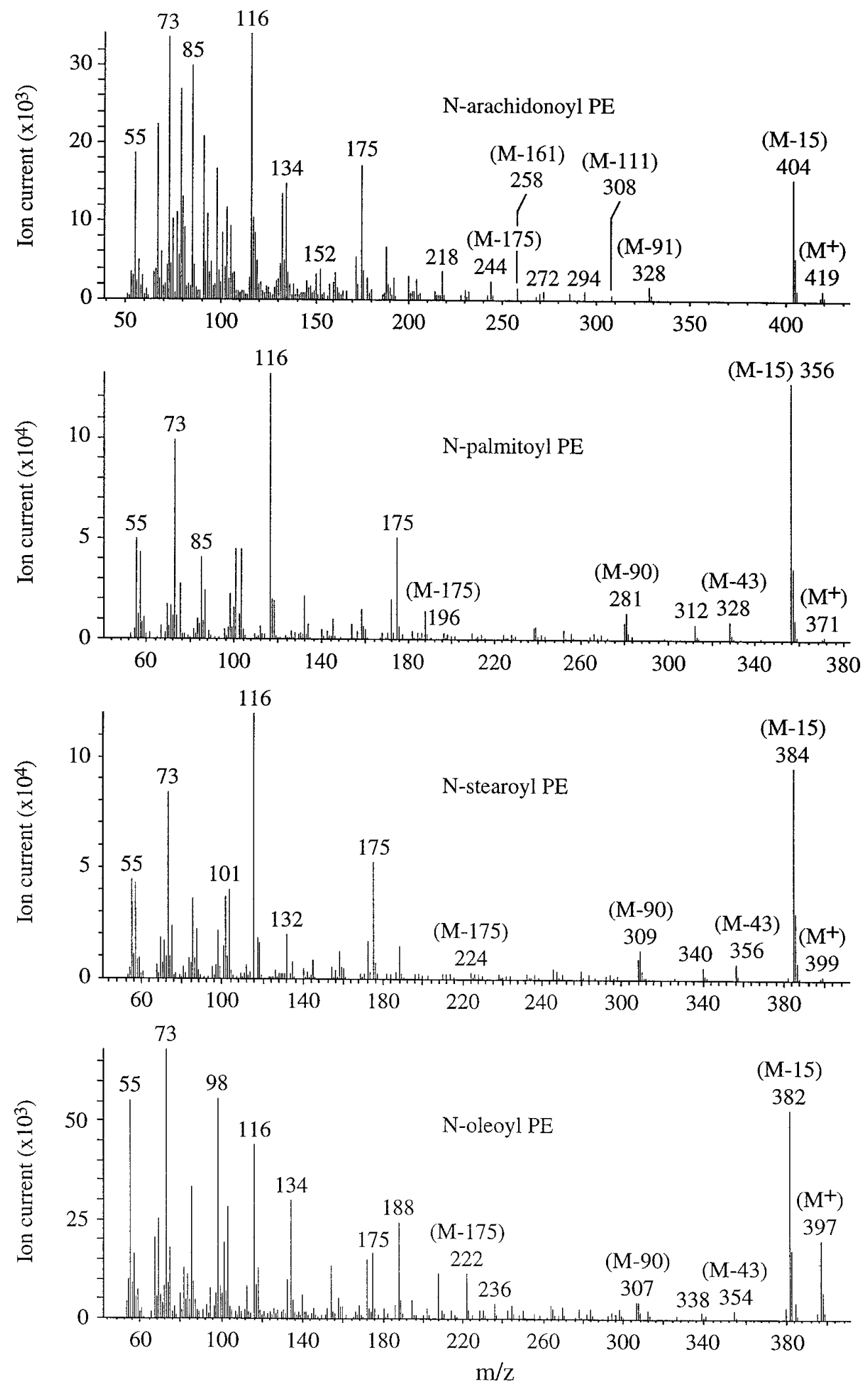

Figure 6. Identification of $N$-arachidonoyl PE and other $N$-acyl PEs produced by brain detergent-solubilized particulate fractions. The fractions $(4.5$ $\mathrm{mg}$ of protein) were incubated for $1 \mathrm{hr}$ at $37^{\circ} \mathrm{C}$, and the lipids were extracted. $N$-acyl PEs were partially purified and digested with PLD, and the NAEs produced in the digestions were analyzed by GC/MS as TMS derivatives. Complete mass spectra were obtained for each product. Results are from one experiment, repeated once with identical results.

containing phospholipid may serve as fatty acyl donor in the $N$-acyltransferase reaction, as recently reported in rat testis (Sugiura et al., 1996a). We incubated, therefore, various brain subcellular fractions in a reaction mixture containing one of three possible $\mathrm{N}$-acyltransferase substrates, radioactively labeled on arachidonate: 1,2-di $\left[{ }^{14} \mathrm{C}\right]$ arachidonoyl PC, 1-stearoyl,2- $\left[{ }^{14} \mathrm{C}\right]$ arachidonoyl PC, and 1-stearoyl,2- $\left[{ }^{14} \mathrm{C}\right]$ arachidonoyl PE. We observed formation of $N$ - $\left[{ }^{14} \mathrm{C}\right]$ arachidonoyl PE with only 1,2-di $\left[{ }^{14} \mathrm{C}\right]$ arachidonoyl PC (Table 4). Such $N$-arachidonoyltransferase activity was $\sim 10$-fold lower than the $N$-palmitoyltransferase activity we measured by using 1,2- 

A. Calcium $(3 \mathrm{mM})$
B. Control

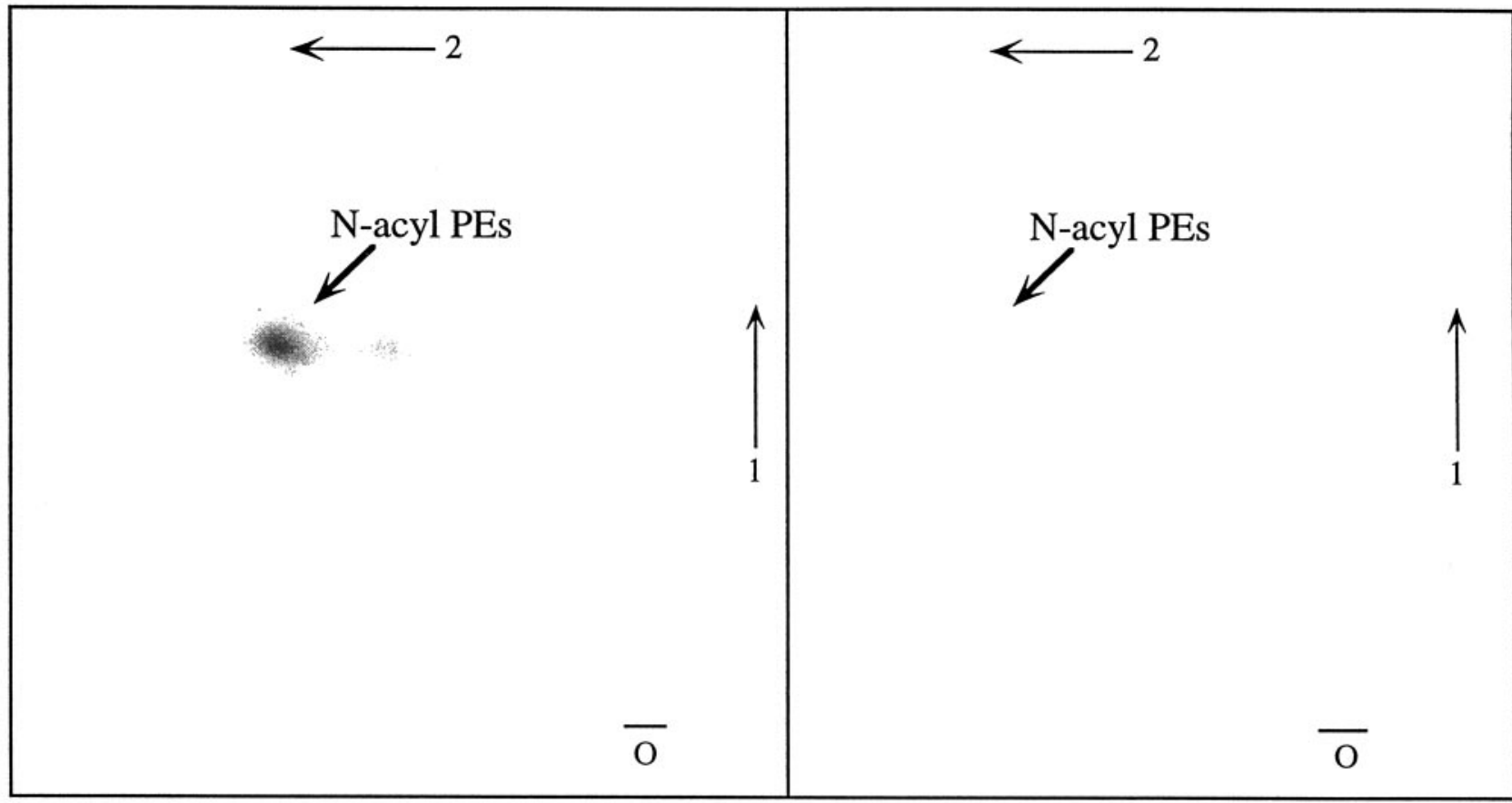

C. Calcium $(3 \mathrm{mM})$

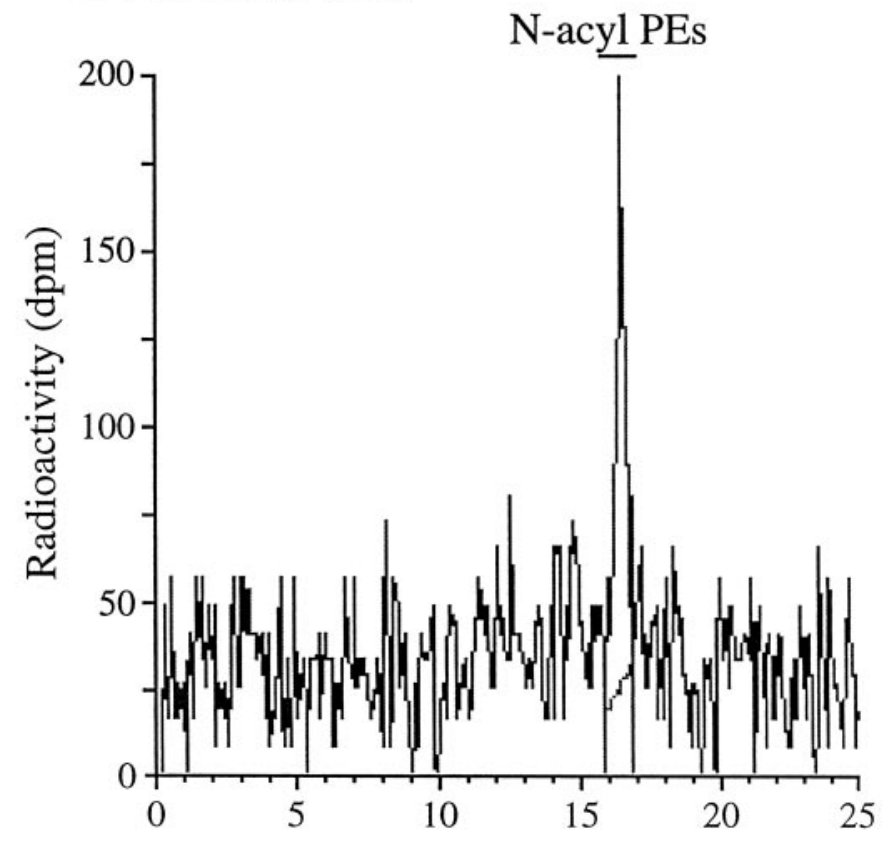

D. Control

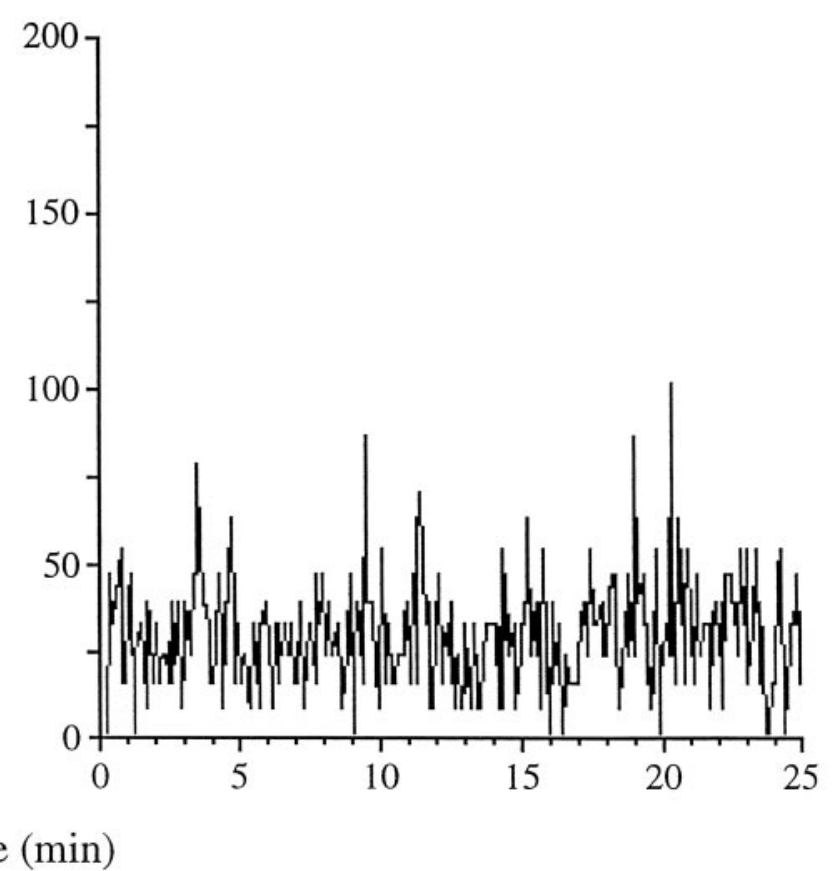

Figure 7. A $\mathrm{Ca}^{2+}$-dependent $N$-acyltransferase activity is present in particulate fractions. The detergent-solubilized fractions were incubated with $3 \mathrm{~mm} \mathrm{Ca}^{2+}(A, C)$ or without $\mathrm{Ca}^{2+}(B, D)$, in a medium containing 1,2-di[ ${ }^{14}$-C]palmitoyl PC as substrate. Radioactive products were identified by $\operatorname{HPTLC}(A, B)$ or by reversed-phase $\operatorname{HPLC}(C, D)$.

di $\left[{ }^{14} \mathrm{C}\right]$ palmitoyl PC. In contrast, incubations with 1-stearoyl,2$\left[{ }^{14} \mathrm{C}\right]$ arachidonoyl PC yielded no $N-\left[{ }^{14} \mathrm{C}\right]$ arachidonoyl PE (Table 4), whereas incubations with 1-stearoyl,2-[ $\left.{ }^{14} \mathrm{C}\right]$ arachidonoyl PE yielded $N$-acyl PEs that were radioactively labeled only on the $s n-2$ acyl ester group, as the PE substrate from which they derived (data not shown).
From these observations, we conclude that $N$-acyltransferase activity in brain can catalyze the transfer to PE of either saturated (e.g., palmitate) or polyunsaturated (e.g., arachidonate) fatty acyl groups, provided that these groups are esterified at the $s n-1$ position of phospholipids. 
Table 4. Subcellular distribution of rat brain $\mathrm{N}$-acyltransferase activity

\begin{tabular}{lcccc}
\multicolumn{5}{c}{ Substrate } \\
\cline { 2 - 5 } Fraction & $\begin{array}{l}\mathrm{di}\left[{ }^{14} \mathrm{C}\right] \\
(16: 0)\end{array}$ & $\begin{array}{l}\mathrm{di}\left[{ }^{14} \mathrm{C}\right] \\
(20: 4)\end{array}$ & $\begin{array}{l}2-\left[{ }^{14} \mathrm{C}\right] \\
(16: 0)\end{array}$ & $\begin{array}{l}2-\left[{ }^{14} \mathrm{C}\right] \\
(20: 4)\end{array}$ \\
\hline Homogenate & $10.0 \pm 2.8$ & $0.5 \pm 0.2$ & $\mathrm{ND}$ & $\mathrm{ND}$ \\
Supernatant 1 & $0.8 \pm 0.4$ & $0.1 \pm 0.1$ & $\mathrm{ND}$ & $\mathrm{ND}$ \\
Particulate & $25.3 \pm 4.7$ & $1.8 \pm 0.5$ & $\mathrm{ND}$ & $\mathrm{ND}$ \\
$\quad$ Soluble & $73.8 \pm 12.4$ & $5.4 \pm 2.2$ & $0.7 \pm 0.4$ & $0.1 \pm 0.1$ \\
Pellet & $4.3 \pm 0.9$ & $0.5 \pm 0.4$ & $\mathrm{ND}$ & $\mathrm{ND}$ \\
Supernatant 2 & $0.3 \pm 0.2$ & $0.05 \pm 0.05$ & $\mathrm{ND}$ & $\mathrm{ND}$ \\
Microsomes & $8.6 \pm 0.3$ & $0.4 \pm 0.2$ & $\mathrm{ND}$ & $\mathrm{ND}$ \\
$\quad$ Soluble & $23.5 \pm 4.2$ & $1 \pm 0.5$ & $\mathrm{ND}$ & $\mathrm{ND}$ \\
Pellet & $0.4 \pm 0.5$ & $0.2 \pm 0.1$ & $\mathrm{ND}$ & $\mathrm{ND}$ \\
\hline
\end{tabular}

$N$-acyltransferase assays were carried out under standard conditions (see Materials and Methods). Radioactive $N$-acyl PEs were purified by monodimensional TLC and quantified by liquid scintillation counting. Results represent the mean \pm SEM of 3-4 experiments. $\quad \operatorname{di}\left[{ }^{14} \mathrm{C}\right] \quad(16: 0), \quad 1,2-\mathrm{di}\left[{ }^{14}\right]$ palmitoyl $\quad \mathrm{PC} ; \quad \operatorname{di}\left[{ }^{14} \mathrm{C}\right] \quad(20: 4), \quad 1,2-$ di $\left[{ }^{14} \mathrm{C}\right]$ arachidonoyl PC; $2-\left[{ }^{14} \mathrm{C}\right](16: 0), 1$-stearoyl,2- $\left[{ }^{14} \mathrm{C}\right]$ palmitoyl PC; $2-\left[{ }^{14} \mathrm{C}\right](20$ : 4), 1-stearoyl,2-[ $\left[{ }^{14} \mathrm{C}\right]$ arachidonoyl PC; ND, not determined.

\section{A novel brain phospholipid serves as precursor for $\mathrm{N}$-arachidonoyl PE}

It is generally thought that, in brain as well as other tissues, arachidonate is mainly esterified at the $s n-2$ position of phospholipids (Shetty et al., 1996). Such selective distribution is in striking contrast with the substrate specificity of brain $N$-acyltransferase, which argues against the participation of this enzyme activity in the biosynthesis of $N$-arachidonoyl PE. Studies by Blank et al. (1985) and Chilton and Murphy (1987) have suggested, however, that small amounts of phospholipid species containing arachidonate at the $s n-1$ position may occur in non-neural tissues. Accordingly, we examined whether similar phospholipids may also be present in rat brain.

The experimental approach we adopted to identify $s n-1$ arachidonoyl phospholipids in brain tissue is depicted in Figure 9A. We isolated brain phospholipids by column chromatography, and digested them with Apis mellifera PLA $_{2}$, an enzyme that selectively hydrolyzes the $s n-2$ fatty acyl ester bond, yielding $s n-1$ lysophospholipids (Kuksis et al., 1983). We extracted the reaction products and incubated them with Bacillus cereus PLC, which hydrolyzes the vicinal phosphate ester bond of $s n-1$ lysophospholipids, yielding $s n-1$ monoacylglycerols. The latter, after conversion to bis-TMS derivatives, are readily resolved by GC, and can be unambiguously identified and distinguished from their $s n-2$ isomers by their typical retention times and mass spectral properties (Murphy, 1993).

Under our conditions, synthetic $s n-1$ arachidonoylglycerol was eluted from the GC at $18.3 \mathrm{~min}$ and yielded the mass spectrum depicted in Figure $9 B$. Informative ions in this mass spectrum included: $\mathrm{m} / \mathrm{z} 522\left(\mathrm{M}^{+}\right), 507$ (M-15, loss of a methyl group), 451 (M-71, loss of a pentyl group), 432 (M-90, loss of [HO-TMS $]^{+}$), 419 (M-103, loss of $\left[\mathrm{CH}_{2}=\mathrm{O}-\mathrm{TMS}\right]^{+}$, fragmentation typical of $s n-1$ MAGs), and 329 (M-193, loss of $\left[\mathrm{CH}_{3}-\mathrm{CH}=\right.$ $\mathrm{CH}-\mathrm{CH}_{2}-\mathrm{CH}=\mathrm{CH}-\mathrm{CH}_{2}-\mathrm{CH}=\mathrm{CH}-\mathrm{CH}_{2}-\mathrm{CH}_{2}-\mathrm{CH}_{2}-$ $\left.\mathrm{CH}_{2}-\mathrm{CH}_{3}\right]^{+}$).

Material derived from the enzymatic hydrolysis of brain phospholipids also contained a component that was eluted at $18.3 \mathrm{~min}$, the mass spectrum of which was very similar to that of synthetic $s n-1$ arachidonoylglycerol, except that it lacked the molecular ion at $\mathrm{m} / \mathrm{z} 522$ (Fig. 9C). Analysis by SIM revealed the presence of the molecular ion, however, and confirmed the identification of this component as $s n-1$ arachidonoylglycerol (Fig. 10).
Table 5. Fatty acids at the $s n-1$ position of brain phospholipids

\begin{tabular}{ll} 
Fatty acid & $\begin{array}{l}\text { Amount } \\
(\% \text { total })\end{array}$ \\
\hline Palmitate & 19.4 \\
Stearate & 56.7 \\
Oleate & 23.3 \\
Arachidonate & 0.5
\end{tabular}

Purified brain phospholipids were sequentially digested with $A$. mellifera $\mathrm{PLA}_{2}$ and $B$. cereus PLC. The resulting $s n-1$ monoacylglycerols were identified by GC/MS. Results, expressed in percentage of total $s n-1$ monoacylglycerols, are from one determination, typical of three.

Table 6. Effects of various divalent and monovalent cations on rat brain $\mathrm{N}$-acyltransferase activity

\begin{tabular}{lrl} 
& \multicolumn{2}{c}{$N$-acyltransferase activity $(\%)$} \\
\cline { 2 - 3 } Ion & \multicolumn{1}{c}{ di- $\left[{ }^{14} \mathrm{C}\right](16: 0) \mathrm{PC}$} & $\mathrm{di}-\left[{ }^{14} \mathrm{C}\right](20: 4) \mathrm{PC}$ \\
\hline $\mathrm{Ca}^{2+}$ & $100 \pm 1.8$ & 100 \\
$\mathrm{Ba}^{2+}$ & $63 \pm 1.6$ & $\mathrm{ND}$ \\
$\mathrm{Sr}^{2+}$ & $94 \pm 4.6$ & $\mathrm{ND}$ \\
$\mathrm{Mg}^{2+}$ & $9 \pm 0.6$ & $\mathrm{ND}$ \\
$\mathrm{BE}^{2+}$ & $4 \pm 0.7$ & 5 \\
$\mathrm{Cd}^{2+}$ & $0.2 \pm 0.1$ & 6.5 \\
$\mathrm{Zn}^{2+}$ & $0.7 \pm 0.7$ & 0.8 \\
$\mathrm{Ag}^{+}$ & $0.1 \pm 1.1$ & 1 \\
$\mathrm{Ca}^{2+}$ plus $\mathrm{Ba}^{2+}$ & $95 \pm 4.3$ & $\mathrm{ND}$ \\
$\mathrm{Ca}^{2+}$ plus $\mathrm{Sr}^{2+}$ & $100 \pm 3.6$ & $\mathrm{ND}$ \\
$\mathrm{Ca}^{2+}$ plus $\mathrm{Mg}^{2+}$ & $95 \pm 4.1$ & $\mathrm{ND}$ \\
$\mathrm{Ca}^{2+}$ plus $\mathrm{Be}^{2+}$ & $5 \pm 0.8$ & 7 \\
$\mathrm{Ca}^{2+}$ plus $\mathrm{Cd}^{2+}$ & $0.1 \pm 0.2$ & 5.5 \\
$\mathrm{Ca}^{2+}$ plus $\mathrm{Zn}^{2+}$ & $0.2 \pm 0.2$ & 2.3 \\
$\mathrm{Ca}^{2+}$ plus $\mathrm{Ag}^{+}$ & $0.8 \pm 0.3$ & 2.5 \\
$\mathrm{EDTA}^{2+}$ & $16 \pm 1.6$ & $10 \pm 4$ \\
$\mathrm{EGTA}^{2}$ & $12 \pm 0.9$ & $17 \pm 0.8$
\end{tabular}

$N$-acyltransferase assays were carried out under standard conditions, as described in Materials and Methods. $\mathrm{CaCl}_{2}$ was used at $3 \mathrm{~mm}$. All other cations, EGTA and EDTA, at $10 \mathrm{~mm}$. Results obtained with 1,2-di $\left[{ }^{14}\right.$-C $]$ palmitoyl PC are from two experiments carried out in triplicate, in which control $N$-acyltransferase activity was $179 \pm 8 \mathrm{pmol} / \mathrm{min} / \mathrm{mg}$ protein. Results obtained with $1,2-\mathrm{di}\left[{ }^{14}-\mathrm{C}\right]$ arachidonoyl PC are from two experiments, in which control $N$-acyltransferase activity was $22 \pm 2$ $\mathrm{pmol} / \mathrm{min} / \mathrm{mg}$ protein.

We conclude from these results that brain tissue contains molecular species of phospholipids in which arachidonate is esterified at the $s n-1$ position of glycerol. Although further experiments are necessary to identify and quantify precisely brain $s n-1$ arachidonoyl phospholipids, initial analyses show that they represent $\sim 0.5 \%$ of the total brain phospholipid pool (Table 5).

\section{Properties and distribution of $\mathrm{N}$-acyltransferase activity}

We investigated some properties of brain $N$-acyltransferase activity in solubilized particulate fractions, using either 1,2di $\left[{ }^{14} \mathrm{C}\right]$ palmitoyl PC or 1,2 -di $\left[{ }^{14} \mathrm{C}\right]$ arachidonoyl PC as fatty acyl donors. With either substrate, the enzyme activity was dependent on protein concentration and incubation time, and was optimal at pH 6 and 8 (data not shown). $\mathrm{Ca}^{2+}$ was necessary for the activity and it could be replaced with $\mathrm{Sr}^{2+}$ and $\mathrm{Ba}^{2+}$, but not with $\mathrm{Mg}^{2+}$ (Table 6). Moreover, several divalent and monovalent cations, including $\mathrm{Be}^{2+}, \mathrm{Zn}^{2+}$, and $\mathrm{Ag}^{+}$, were potent in inhibiting the activity (Table 6).

The effects of various protein-modifying reagents on brain 
Figure 8. Identification of brain $\mathrm{N}$-acyltransferase by FPLC. Samples of the detergent-solubilized particulate fractions were injected into a MonoQ column, and the proteins were eluted with a gradient of $\mathrm{NaCl}$ from $50 \mathrm{~mm}$ to $1 \mathrm{M}$. The column eluate was collected in $1 \mathrm{~min}$ fractions, and $N$-acyltransferase activity measured as described in Materials and Methods. Results are from one experiment, representative of three.

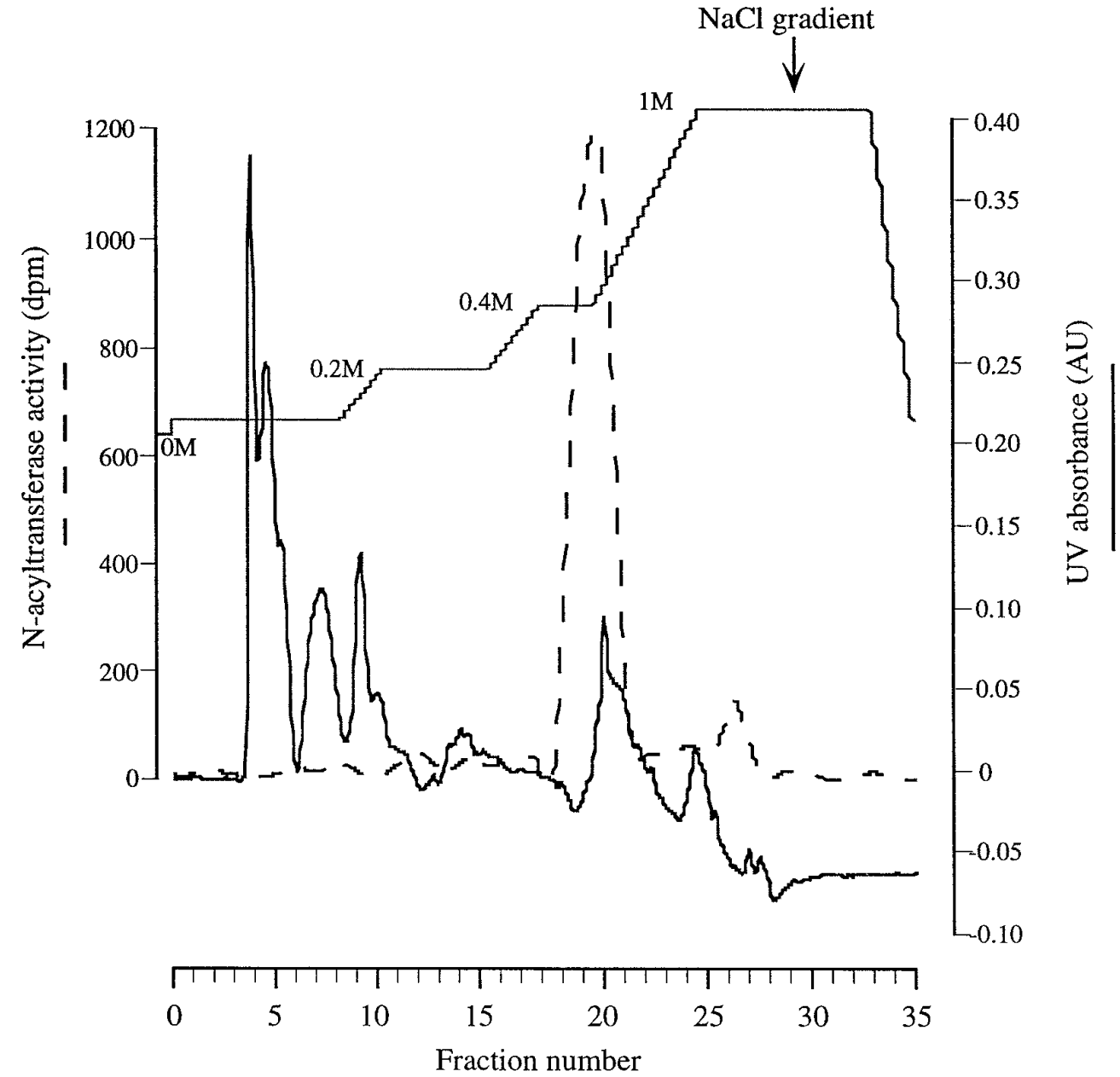

$\mathrm{N}$-acyltransferase activity are summarized in Table 7. Chemicals that alkylate serine (e.g., PMSF), cysteine [dithionitrobenzoic acid (DTNB)], and histidine [ $p$-bromophenacylbromide (pBPB)] inhibited the activity, whereas a cystine-reducing agent (DTT) enhanced it significantly. In the study by Sugiura et al. (1996b), brain $N$-acyltransferase activity was not inhibited by $1 \mathrm{~mm}$ PMSF; the origin of this discrepancy is at present unknown. The effect of pBPB, a histidine-alkylating agent that potently inhibits membrane-bound $\mathrm{PLA}_{2} \mathrm{~s}$, prompted us to screen additional $\mathrm{PLA}_{2}$ inhibitors for their ability to interfere with $N$-acyltransferase activity. We found that (E)-6-(bromomethylene)-tetrahydro-3-(1naphthalenyl)-2H-pyran-2-one (BTNP), an inhibitor of $\mathrm{Ca}^{2+}$ independent PLA $_{2}$ (Hazen et al., 1991), inactivated the enzyme with an $\mathrm{IC}_{50}$ of $\sim 2 \mu \mathrm{M}$ (Table 7 ).

The distribution of $N$-acyltransferase activity in particulate fractions from various rat tissues, assayed with either 1,2$\mathrm{di}\left[{ }^{14} \mathrm{C}\right]$ palmitoyl PC or $1,2-\mathrm{di}\left[{ }^{14} \mathrm{C}\right]$ arachidonoyl PC, is illustrated in Figure $11 A$. We found highest levels of activity in brain and testis. Lower but significant levels were observed also in skeletal muscle, whereas little or no activity was detected in other tissues. Within the CNS, differences were less marked: highest levels of $N$-acyltransferase activity were measured in the brainstem; intermediate levels were measured in the cortex, striatum, cerebellum, hippocampus, and medulla; and lowest levels were measured in olfactory tubercle, thalamus, hypothalamus, and olfactory bulb (Fig. 11B).

\section{$\mathrm{N}$-Acyltransferase activity mediates $\mathrm{N}$-arachidonoyl PE formation in intact neurons}

We have previously reported that, in rat cortical mixed cultures, biosynthesis of $N$-acyl PEs is enhanced in a $\mathrm{Ca}^{2+}$-dependent manner by ionomycin, a $\mathrm{Ca}^{2+}$ ionophore, or by membranedepolarizing agents (Cadas et al., 1996a). These results suggested that a $\mathrm{Ca}^{2+}$-activated $N$-acyltransferase activity may catalyze $N$-acyl PE biosynthesis in intact neurons. This possibility could not be stringently tested, however, because pharmacological inhibitors effective $N$-acyltransferase inhibitor in vitro prompted us to examine its effects on $N$-acyl PE biosynthesis in intact neurons.

In a first series of experiments, we used cortical mixed cultures that had been labeled by incubation with $\left[{ }^{3} \mathrm{H}\right]$ ethanolamine. We stimulated the cultures with $1 \mu \mathrm{M}$ ionomycin and measured the radioactivity associated with $N$-acyl PEs after TLC purification. As reported, $N$-acyl $\left[{ }^{3} \mathrm{H}\right] \mathrm{PE}$ levels in ionomycin-treated cultures were approximately threefold greater than those of untreated controls (Table 8). This effect was almost completely abolished when the neurons were exposed to $25 \mu \mathrm{M}$ BTNP (Table 8).

To examine the effects of BTNP on $N$-arachidonoyl PE biosynthesis, in subsequent experiments we stimulated the cultures, purified the $N$-acyl PEs, and quantified them by GC/MS after PLD digestion. We found that the cultures contained $0.82 \mathrm{pmol} /$ dish of $N$-arachidonoyl PE when unstimulated, $2.54 \mathrm{pmol} / \mathrm{dish}$ when stimulated with ionomycin, and $0.95 \mathrm{pmol} / \mathrm{dish}$ when stimof this enzyme were not available. The finding that BTNP is an 
A.

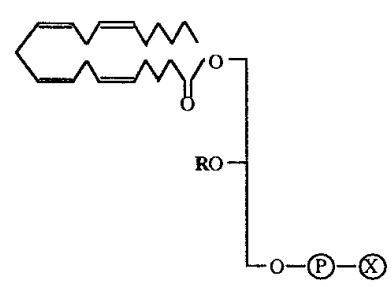

$s n-1$ arachidonoylphospholipid

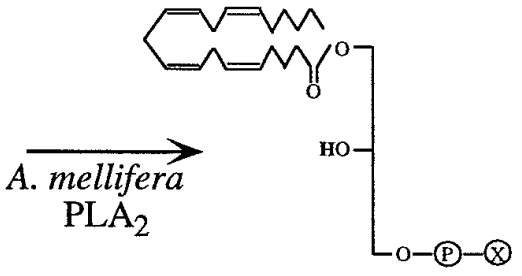

$s n-1$ arachidonoyllysophospholipid

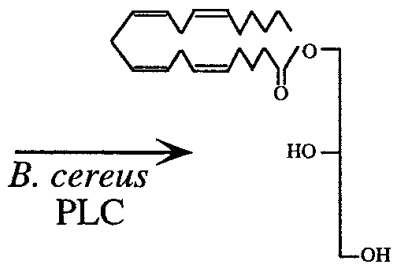

$s n-1$ arachidonoylglycerol

\section{B. Synthetic}

:

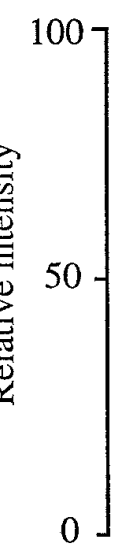

73

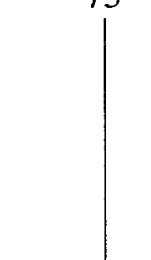

50

100

55|| $103|117| \frac{147}{\mid} \mid$
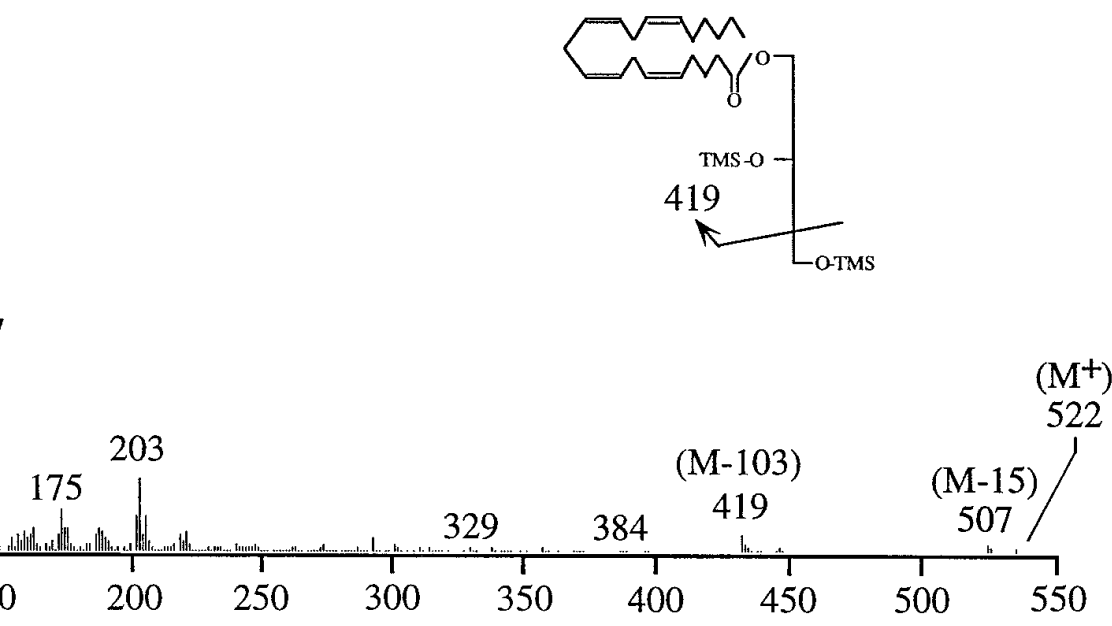

C. Brain-derived

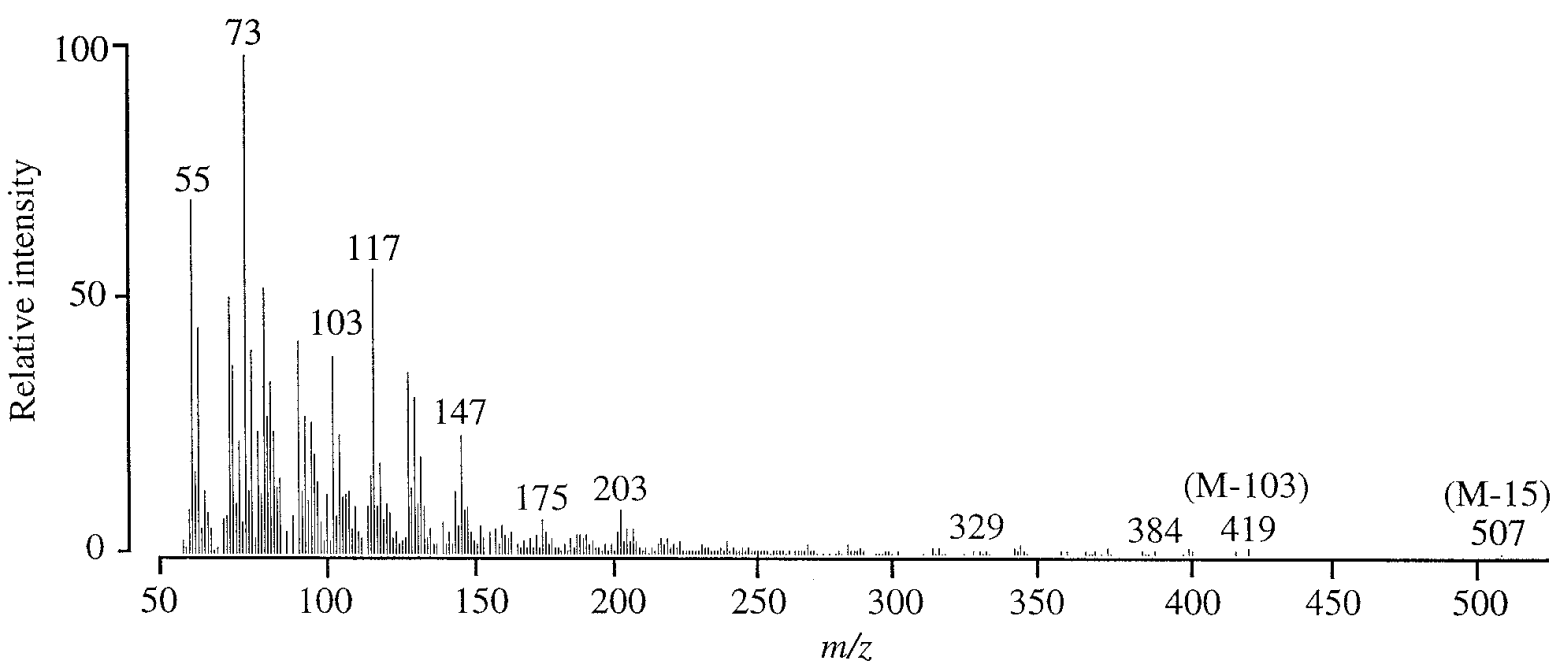

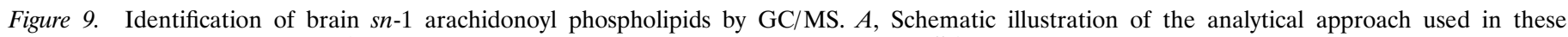

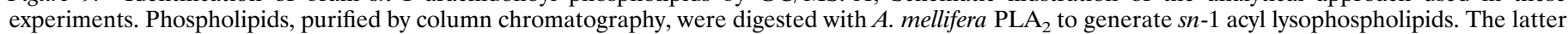

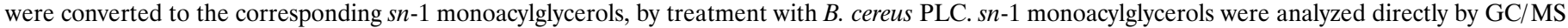

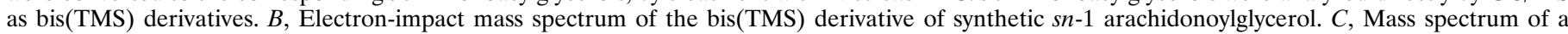
brain-derived component with the GC retention time of bis(TMS) $s n-1$ arachidonoyl glycerol. 


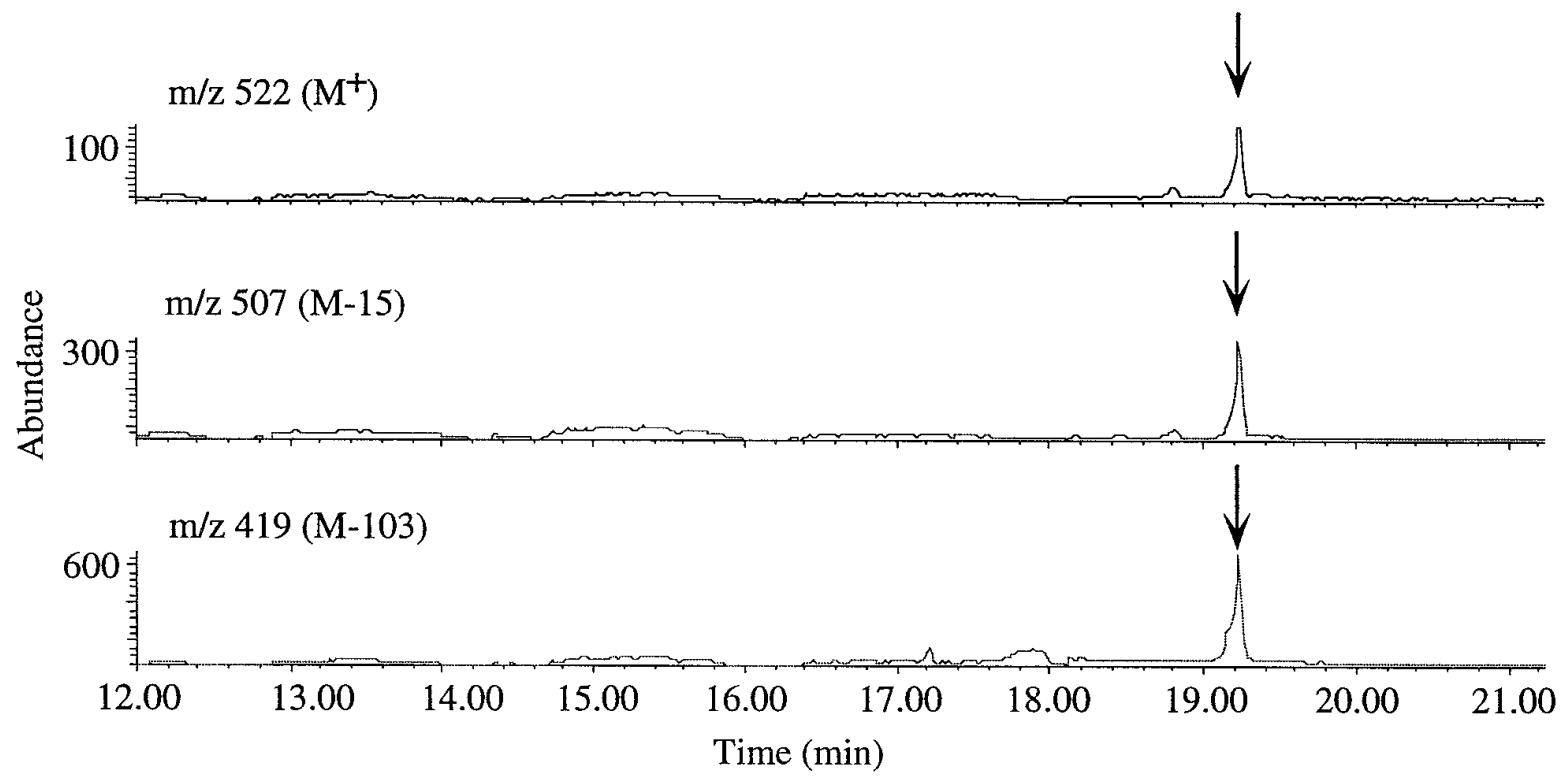

Figure 10. Identification of brain $s n-1$ arachidonoyl phospholipids by SIM. Three diagnostic ions were chosen from the mass spectrum of the bis(TMS)-derivative of $s n-1$ arachidonoylglycerol: m/z $522\left(\mathrm{M}^{+}\right), \mathrm{m} / \mathrm{z} 507$ (M-15), and m/z 419 (M-103, typical of $s n-1$ arachidonoylglycerol). The arrow indicates the retention time of standard bis(TMS) $s n-1$ arachidonoyl glycerol. Results are from one determination, representative of three.

\begin{tabular}{|c|c|c|c|}
\hline \multirow[b]{2}{*}{ Inhibitor } & \multirow{2}{*}{$\begin{array}{l}\text { Concentration } \\
(\mathrm{mM})\end{array}$} & \multicolumn{2}{|c|}{$N$-acyltransferase activity $(\%)$} \\
\hline & & $\mathrm{di}-\left[{ }^{14} \mathrm{C}\right](16: 0) \mathrm{PC}$ & $\mathrm{di}-\left[{ }^{14} \mathrm{C}\right](20: 4) \mathrm{PC}$ \\
\hline Control & & 100 & 100 \\
\hline DNPP & 1 & $76 \pm 0.5$ & ND \\
\hline DIFP & 1 & $61 \pm 1$ & ND \\
\hline DTNB & 1 & $0.6 \pm 0.2$ & 6.5 \\
\hline DTT & 1 & $139 \pm 1.2$ & 150 \\
\hline \multirow[t]{2}{*}{ pBPB } & 0.025 & $74 \pm 0.8$ & ND \\
\hline & 0.1 & $1 \pm 0.3$ & 14.5 \\
\hline \multirow[t]{3}{*}{ BTNP } & 0.001 & $91 \pm 1$ & $62 \pm 1$ \\
\hline & 0.010 & $13 \pm 2$ & $8 \pm 3$ \\
\hline & 0.025 & $13 \pm 2$ & $10 \pm 1$ \\
\hline \multirow[t]{2}{*}{ PMSF } & 0.1 & $69 \pm 0.3$ & ND \\
\hline & 1 & $9 \pm 1.0$ & 13.5 \\
\hline PBA & 1 & $44 \pm 5.2$ & 45 \\
\hline O-Phe & 0.2 & $106 \pm 1.0$ & ND \\
\hline
\end{tabular}

$N$-acyltransferase assays were carried out under standard conditions, as described in Materials and Methods. Control $N$-acyltransferase activities and number of experimental determinations are as in Table 6. DNPP, diethyl $p$-nitrophenylphosphate (Ser-His reagent); DIFP, diisopropylfluorophosphate (Ser-His reagent); DTNB, dithionitrobenzoic acid (Cys reagent); O-Phe, o-phenanthroline ( $\mathrm{Zn}^{2+}$ chelator) Drugs were diluted in standard assay buffer from DMSO or methanol stock solutions, yielding maximal solvent concentrations of $0.1 \%$, which had no effect on $N$-acyltransferase activity.

ulated with ionomycin in the presence of $25 \mu \mathrm{M}$ BTNP. Together, these results support an essential role for $N$-acyltransferase activity in the biosynthesis of $N$-arachidonoyl PE and other $N$-acyl PEs in situ.

\section{DISCUSSION}

Experiments with rat brain neurons in primary cultures have suggested that anandamide formation may result from the hydrolytic cleavage of a membrane phospholipid precursor, $N$-arachidonoyl PE (Fig. 12) (Di Marzo et al., 1994; Cadas et al.,
Table 8. Effect of $N$-acyltransferase inhibition on $N$-acyl $\left[{ }^{3} \mathrm{H}\right] \mathrm{PE}$ biosynthesis in cultures of rat cortical neurons

\begin{tabular}{llll} 
Condition & $\begin{array}{l}\text { Concentration } \\
(\mathrm{mM})\end{array}$ & $\begin{array}{l}\left.N \text {-acyl[ }{ }^{3} \mathrm{H}\right] \mathrm{PE} \\
(\mathrm{dpm} / \mathrm{dish})\end{array}$ & $(\%)$ \\
\hline Control & & $2825 \pm 364$ & 100 \\
Ionomycin & 1 & $9038 \pm 1114$ & 320 \\
Ionomycin/BTNP & $1 / 25$ & $4347 \pm 562$ & 154
\end{tabular}

Cultures of rat cortical neurons, prelabeled with $\left[{ }^{3} \mathrm{H}\right]$ ethanolamine, were incubated for $10 \mathrm{~min}$ in DMEM with or without BTNP $(25 \mu \mathrm{M})$, and then incubated for additional 10 min with ionomycin $(1 \mu \mathrm{M})$ and BTNP, as indicated. $N-\left[{ }^{3} \mathrm{H}\right]$ acyl PE were purified by monodimensional TLC and quantified by liquid scintillation counting. Results are from one experiment performed in four separate cultures, repeated once with identical results.

1996a). In the present study, we have considered three aspects of this hypothetical mechanism that are essential to establish its physiological relevance. First, we have determined whether $N$-arachidonoyl PE is present in adult brain tissue. Second, we have examined the enzyme activity and lipid substrates that participate in the biosynthesis of $N$-arachidonoyl PE in vitro. Finally, we have assessed the contribution of this enzyme activity to $N$-arachidonoyl PE biosynthesis in intact neurons.

\section{Occurrence of anandamide and $\mathbf{N}$-arachidonoyl PE in brain tissue}

Like other phospholipid metabolites, $N$-acyl PEs and NAEs accumulate rapidly in the CNS after the inception of an ischemic injury (Schmid et al., 1995; Kempe et al., 1996). This response, likely caused by postischemic rises in the concentration of free $\mathrm{Ca}^{2+}$, may confuse quantitative analysis unless appropriate precautions are taken to prevent it. In our experiments, we have immersed the heads of the animals in liquid nitrogen within $2 \mathrm{sec}$ of decapitation, a procedure that has been used extensively to determine basal levels of free fatty acids and diacylglycerols in brain tissue (Aveldano de Caldironi and Bazan, 1979; DeMedio et al., 1980; Tang and Sun, 1985). Then, by using an analytical approach that combines HPLC purification and GC/MS identifi- 

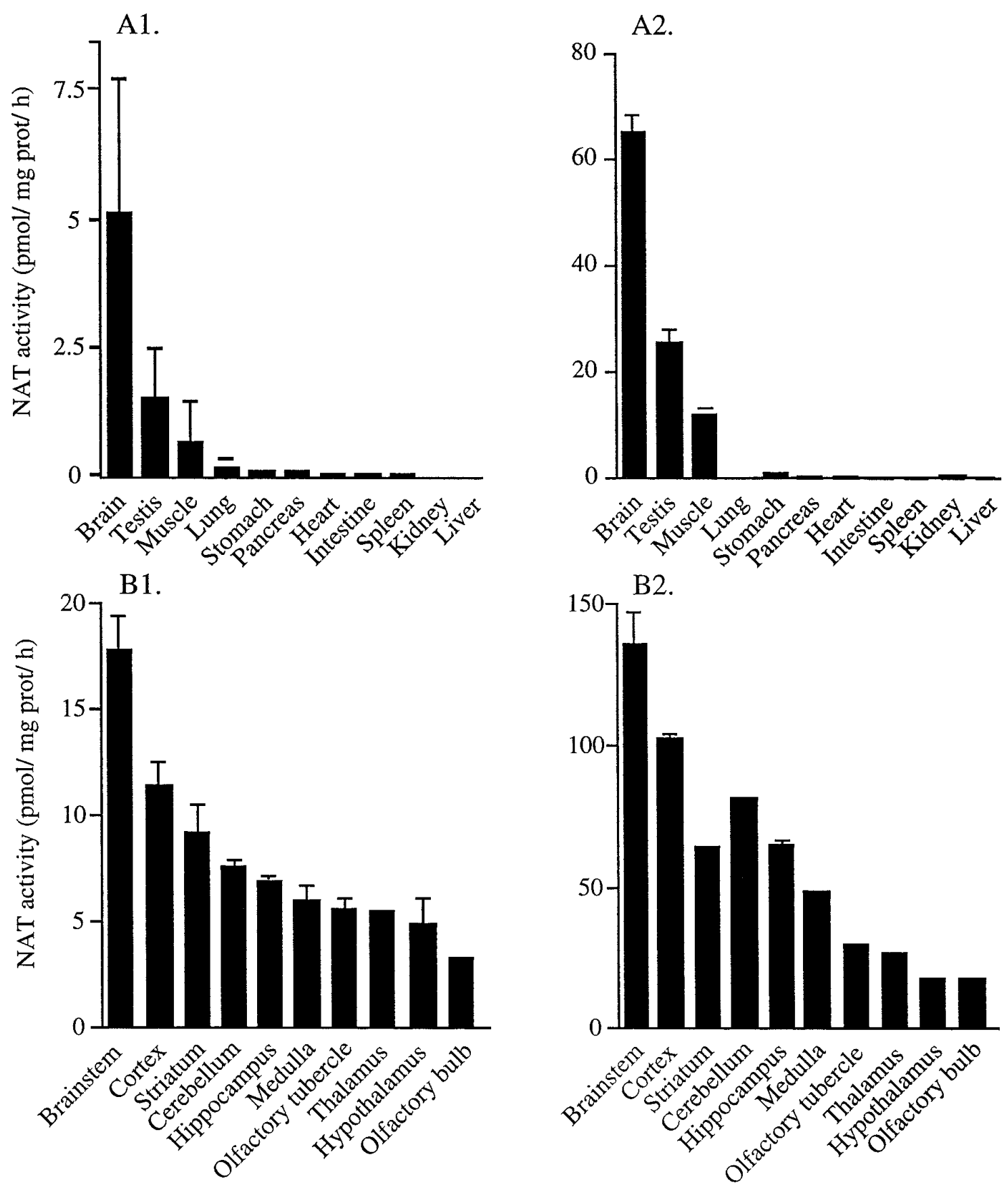

Figure 11. Distribution of $N$-acyltransferase activity in detergent-solubilized particulate fractions from various tissues $(A)$ and from various brain regions $(B)$ of the rat. $N$-acyltransferase assays were carried out under standard conditions (see Materials and Methods), using either 1,2 -di $\left[{ }^{14} \mathrm{C}\right]$ arachidonoyl PC $(A 1, B 1)$ or $1,2-$ di $\left[{ }^{14} \mathrm{C}\right]$ palmitoyl PC $(A 2, B 2)$ as fatty acyl donor. Radioactive $N$-acyl PEs were purified by monodimensional TLC $(A 1, A 2)$ or column chromatography $(B 1, B 2)$ (see Materials and Methods). TLC purification was used in the experiments on tissue distribution because a PLA activity was present in some tissues, which produced large quantities of $\left[{ }^{14} \mathrm{C}\right]$ fatty acids, interfering with the assay by column chromatography (data not shown). Results are expressed as the mean \pm SEM of at least three experiments.

cation, we have shown that both anandamide and $N$-arachidonoyl $\mathrm{PE}$ are present in brain under these conditions.

On average, we measured $11 \pm 7 \mathrm{pmol}$ of anandamide/gm of wet brain tissue, a value very similar to those obtained very recently by Schmid et al. (1995; corrected in 1996b) in pig brain (17.3 pmol/gm) and cow brain $(11.5 \mathrm{pmol} / \mathrm{gm})$, by Sugiura et al. (1996b) in rat brain $(4.3 \pm 1.1 \mathrm{pmol} / \mathrm{gm})$, and by Felder et al. (1996) in various regions of rat (20-29 pmol/gm) and human brain (25-148 pmol/gm). Such anandamide levels should be well within the detection limit of the GC/MS isotope dilution method developed by Kempe et al. (>3.5 pmol/gm; 1996). These authors did not detect anandamide in their analyses of rat brain tissue, however; differences in the extraction and purification of lipids may account for this discrepancy.

Estimating the content of anandamide in the CNS may be useful to delineate its possible roles in neural signaling. The low amounts measured in our study accord better with those obtained with lipid mediators (e.g., the eicosanoids, produced in stimulated 


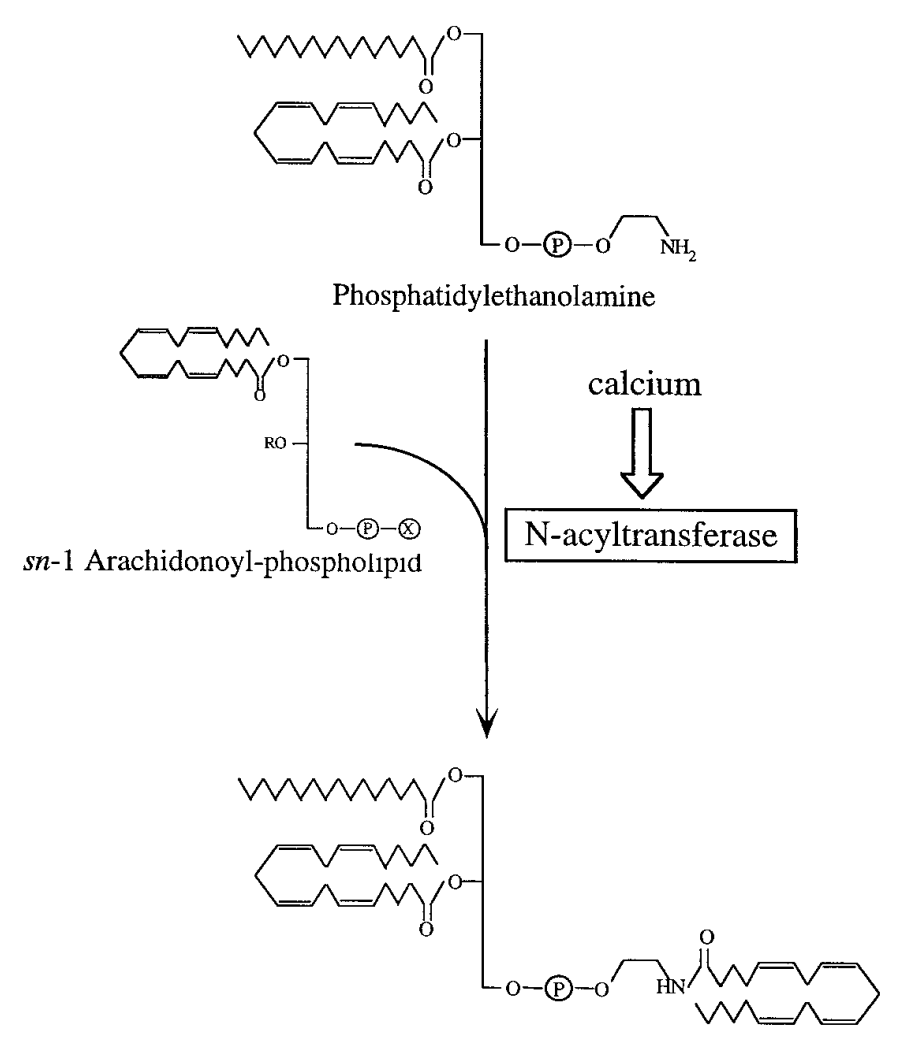

$\mathrm{N}$-arachidonoyl PE

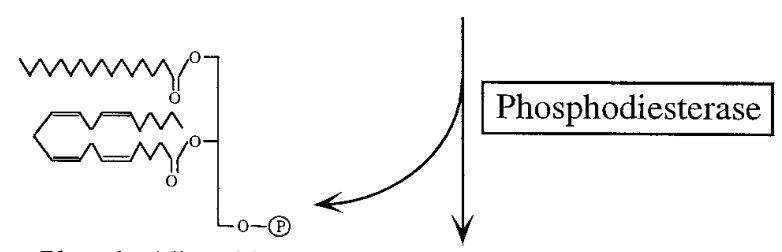

Phosphatidic acid

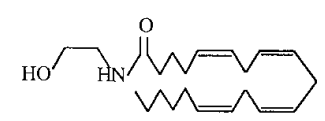

Anandamide

Figure 12. Hypothetical model of $N$-arachidonoyl PE biosynthesis in rat brain tissue. Rises in intracellular $\mathrm{Ca}^{2+}$ concentration produced by neuronal activity may stimulate a $N$-acyltransferase activity, which catalyzes the transfer of arachidonate from $s n-1$ arachidonoyl phospholipids (possibly PC) to PE. $\mathrm{Ca}^{2+}$ may also stimulate a D-type phosphodiesterase activity (phospholipase D), which cleaves the distal phosphodiester bond of $N$-arachidonoyl PE, forming anandamide. The mass of $N$-arachidonoyl $\mathrm{PE}$ found in brain is only approximately twofold greater than the mass of anandamide, suggesting that sustained anandamide formation in neurons may require the concomitant stimulation by $\mathrm{Ca}^{2+}$ of $N$-acyltransferase and phosphodiesterase activities.

brain tissue at $10-100 \mathrm{pmol} / \mathrm{gm}$ ) and neuropeptides (e.g., vasoactive intestinal peptide, present at $1-150 \mathrm{pmol} / \mathrm{gm})$, than with those obtained with neurotransmitters (e.g., $\gamma$-aminobutyric acid, $\approx 1 \mu \mathrm{mol} / \mathrm{gm}$; dopamine, $\approx 4 \mathrm{nmol} / \mathrm{gm}$ ) (Smith et al., 1975; Takahashi and Otsuka, 1975; Lorén et al., 1976; Lindgren et al., 1984; Miyamoto et al., 1987). Thus, our results reinforce the notion that anandamide may act in the CNS more as a modulatory substance (e.g., in an autocrine fashion) than as a classical neurotransmitter, a possibility that finds further support in its nonvesicular mechanism of release (Di Marzo et al., 1994; Cadas et al., 1996b).
A comparison of the brain levels of anandamide with those of $N$-arachidonoyl PE may help clarify the metabolic relationship between these lipid products. The content of $N$-arachidonoyl PE (22 $\pm 16 \mathrm{pmol} / \mathrm{gm})$, twice as large that of anandamide, supports its proposed role as anandamide precursor. Yet, the relatively small proportions of this precursor pool may indicate the existence of an active biochemical mechanism for the resynthesis of $N$-arachidonoyl PE depleted during neural activity. In support of this possibility, we have shown previously that biosynthesis of $N$-acyl PEs in cortical mixed cultures is stimulated by physiologically relevant rises in intracellular $\mathrm{Ca}^{2+}$, elicited by membranedepolarizing agents or by $\mathrm{Ca}^{2+}$ ionophore (Cadas et al., 1996a).

\section{Mechanism of $\mathrm{Ca}^{2+}$-dependent $\mathrm{N}$-arachidonoyl PE biosynthesis}

How may intracellular $\mathrm{Ca}^{2+}$ levels regulate $N$-arachidonoyl PE biosynthesis? Extensive investigations by the laboratory of Schmid and colleagues have shown that formation of other $N$-acyl PEs is mediated by a $\mathrm{Ca}^{2+}$-dependent $N$-acyltransferase activity, which transfers a saturated or monounsaturated fatty acyl group from the $s n-1$ position of phospholipids to the primary amino group of PE (Reddy et al., 1983; Schmid et al., 1990; Schmid et al., 1996a). Our results support this general mechanism, and extend it to $N$-arachidonoyl PE (Fig. 12).

We have identified and partially characterized a $\mathrm{Ca}^{2+}$. dependent enzyme activity that catalyzes the biosynthesis of $N$ - $\left[{ }^{14} \mathrm{C}\right]$ arachidonoyl PE, when a phospholipid containing $\left[{ }^{14} \mathrm{C}\right] \mathrm{ar}-$ achidonate at the $s n-1$ position is provided as fatty acyl donor. We have also demonstrated that $s n-1$ arachidonoyl phospholipids are normal, albeit quantitatively minor, components of brain phospholipids. Thus, our results indicate that brain tissue contains the complement of enzymatic activity and lipid substrates necessary for the biosynthesis of $N$-arachidonoyl PE. While the present study was being drafted, Sugiura et al. (1996b) reported on the occurrence of a similar enzyme activity and phospholipid substrate in rat brain. Further experiments are necessary to determine whether the $N$-arachidonoyltransferase activity described in these studies resides in the same enzyme responsible for the biosynthesis of saturated and monounsaturated $N$-acyl PEs.

The discrete tissue localization of $N$-acyltransferase activity, concentrated in brain and testis, and its relative enrichment in select areas of the CNS, highlight its potential importance in neural signaling. This distribution only partially parallels that of CB1 cannabinoid receptors. In fact, whereas these receptors are densely expressed in cortex, hippocampus, cerebellum, and striatum (regions in which $N$-acyltransferase activity is also relatively high), they are only sparsely present in the brainstem (the region of highest enzyme activity; Herkenham et al., 1991). A possible explanation for this difference is that anandamide may have additional effects that are not mediated by the activation of any of the known cannabinoid receptor subtypes (Venance et al., 1995).

Stimulation of $N$-acyltransferase activity may account for the $\mathrm{Ca}^{2+}$-dependent increase in $\mathrm{N}$-arachidonoyl PE biosynthesis observed when cortical mixed cultures are exposed to membrane depolarizing agents or $\mathrm{Ca}^{2+}$ ionophore (Cadas et al., 1996a). In agreement with this conclusion, we observed that BTNP, a drug that we found to inhibit $N$-acyltransferase activity in vitro, also prevents ionomycin-induced $N$-arachidonoyl PE biosynthesis in these cultures. 


\section{Physiological significance of the $\mathbf{N}$-acyltransferase pathway}

The preceding discussion has focused on the $N$-acyltransferase pathway as a possible biochemical mechanism for the formation of $\mathrm{N}$-arachidonoyl PE and anandamide, but it is important to note that these lipids represent only a small fraction of the $N$-acyl PEs and NAEs found in brain. What, if any, are the physiological roles of saturated and monounsaturated $N$-acyl PEs and NAEs? Although it is not yet possible to provide an adequate answer to this question, several findings indicate that these lipids may be biologically active. For example, $N$-palmitoylethanolamine was shown to protect cerebellar granule neurons from excitotoxic death and to prevent antigen-induced mast cell activation, possibly by binding to CB2-like cannabinoid receptors (Facci et al., 1995; Skaper et al., 1996). Moreover, $N$-oleoylethanolamine and $N$-linoleoylethanolamine were found to inhibit anandamide degradation in vitro, as well as in intact astrocytes in culture (di Tomaso et al., 1996), and pharmacological effects of these and other NAEs on cell membrane properties have been reported (Gulaya et al., 1993). These different lines of evidence suggest that the NAEs may constitute a family of lipid signaling molecules, which may serve multiple physiopathological functions in the CNS.

\section{REFERENCES}

Aveldano de Caldironi MI, Bazan NG (1979) $\alpha$-Methyl- $p$-tyrosine inhibits the production of free arachidonic acid and diacylglycerols in brain after a single electroconvulsive shock. Neurochem Res 4:213-221.

Blank ML, Cress EA, Robinson M, Snyder F (1985) Metabolism of unique diarachidonoyl and linoleoylarachidonoyl species of ethanolamine and choline phosphoglycerides in rat testes. Biochim Biophys Acta 833:366-371.

Cadas H, Gaillet S, Beltramo M, Venance L, Piomelli D (1996a) Biosynthesis of an endogenous cannabinoid precursor in neurons and its control by calcium and cAMP. J Neurosci 16:3934-3942.

Cadas H, Schinelli S, Piomelli D (1996b) Membrane localization of $N$-acylphosphatidylethanolamine in central neurons: studies with exogenous phospholipases. J Lipid Med Cell Signal 14:63-70.

Chilton FH, Murphy RC (1987) Stimulated production and natural occurrence of 1,2-diarachidonoylglycerophosphorylcholine in human neutrophils. Biochem Biophys Res Commun 145:1126-1133.

Crawley JN, Corwin RL, Robinson JK, Felder CC, Devane WA, Axelrod J (1993) Anandamide, an endogenous ligand of the cannabinoid receptor, induces hypomotility and hypothermia in vivo in rodents. Pharmacol Biochem Behav 46:967-972.

Deadwyler SA, Hampson RE, Bennett BA, Edwards TA, Mu J, Pacheco MA, Ward SJ, Childers SR (1993) Cannabinoids modulate potassium current in cultured hippocampal neurons. Receptors Channels $1: 121-134$

Deadwyler SA, Hampson RE, Mu J, Whyte A, Childers S (1995) Cannabinoids modulate voltage sensitive potassium A-current in hippocampal neurons via a cAMP-dependent process. J Pharmacol Exp Ther 273:734-743.

DeMedio GE, Goracci G, Horrocks LA, Lazarewicz JW, Mazzari S, Porcellati G, Strosznajder J, Trovarelli G (1980) The effect of transient ischemia on fatty acid and lipid metabolism in the gerbil brain. Ital J Biochem 29:412-432.

Desarnaud F, Cadas H, Piomelli D (1995) Anandamide amidohydrolase activity in rat brain microsomes: identification and partial characterization. J Biol Chem 270:6030-6035.

Deutsch DG, Chin S (1993) Enzymatic synthesis and degradation of anandamide, a cannabinoid receptor agonist. Biochem Pharmacol 46:791-796.

Devane WA, Axelrod J (1994) Enzymatic synthesis of anandamide, an endogenous ligand for the cannabinoid receptor, by brain membranes. Proc Natl Acad Sci USA 91:6698-6701.

Devane WA, Hanus L, Breuer A, Pertwee RG, Stevenson LA, Griffin G, Gibson D, Mandelbaum D, Etinger A, Mechoulam R (1992) Isolation and structure of a brain constituent that binds to the cannabinoid receptor. Science 258:1946-1949.
Dewey WL (1986) Cannabinoid pharmacology. Pharmacol Rev $38: 151-178$.

Di Marzo V, Fontana A, Cadas H, Schinelli S, Cimino G, Schwartz J-C, Piomelli D (1994) Formation and inactivation of endogenous cannabinoid anandamide in central neurons. Nature 372:686-691.

di Tomaso E, Beltramo M, Piomelli D (1996) Brain cannabinoids in chocolate. Nature 382:677-678.

Facci L, Dal Toso R, Romanello S, Buriani A, Skaper SD, Leon A (1995) Mast cells express a peripheral cannabinoid receptor with differential sensitivity to anandamide and palmitoylethanolamine. Proc Natl Acad Sci USA 92:3376-3380.

Felder CC, Briley EM, Axelrod J, Simpson JT, Mackie K, Devane WA (1993) Anandamide, an endogenous cannabimimetic eicosanoid, binds to the cloned human cannabinoid receptor and stimulates receptormediated signal transduction. Proc Natl Acad Sci USA 90:7656-7660.

Felder CC, Nielsen A, Briley EM, Palkovits M, Priller J, Axelrod J, Nguyen DN, Richardson JM, Riggin RM, Koppel GA, Paul SM, Becker GW (1996) Isolation and measurement of the endogenous cannabinoid receptor agonist, anandamide, in brain and peripheral tissues of human and rat. FEBS Lett 393:231-235.

Folch J, Lees M, Sloane Stanley GH (1957) A simple method for the isolation and purification of total lipids from animal tissues. J Biol Chem 226:497-509.

Fride E, Mechoulam R (1993) Pharmacological activity of the cannabinoid receptor agonist, anandamide, a brain constituent. Eur J Pharmacol 321:313-314.

Gulaya NM, Melnik AA, Balkov DI, Volkov GL, Vysotskiy MV, Vaskovsky VE (1993) The effect of long-chain $N$-acylethanolamines on some membrane-associated functions of neuroblastoma C1300 N18 cells. Biochim Biophys Acta 1152:280-288.

Hazen SL, Zupan LA, Weiss RH, Getman DP, Gross RW (1991) Suicide inhibition of canine myocardial cytosolic calcium-independent phospholipase $\mathrm{A}_{2}$. J Biol Chem 266:7227-7232.

Herkenham M, Lynn AB, Johnson MR, Melvin LS, de Costa BR, Rice KC (1991) Characterization and localization of cannabinoid receptors in rat brain: a quantitative in vitro autoradiographic study. J Neurosci 11:563-583.

Herkenham M, Lynn AB, Little MD, Johnson MR, Melvin LS, de Costa BR, Rice KC (1990) Cannabinoid receptor localization in brain. Proc Natl Acad Sci USA 87:1932-1936.

Hollister LE (1986) Health aspects of cannabis. Pharmacol Rev 38:1-20.

Howlett AC (1995) Pharmacology of cannabinoid receptors. Ann Rev Pharmacol Toxicol 35:607-634.

Huettner JE, Baughman RW (1986) Primary culture of identified neurons from the visual cortex of postnatal rats. J Neurosci 6:3044-3060.

Kempe K, Hsu F-F, Turk J (1996) Isotope dilution mass spectrometric measurements indicate that arachidonoylethanolamine, the proposed endogenous ligand of the cannabinoid receptor, accumulates in rat brain tissue post mortem but is contained at low levels or is absent in fresh tissue. J Biol Chem 271:17287-17295.

Kruszka KK, Gross RW (1994) The ATP- and CoA-independent synthesis of arachidonoylethanolamine. J Biol Chem 269:14345-14348.

Kuksis A, Marai L, Myher JJ (1983) Strategy of glycerophospholipid separation and quantitation by complementary analytical techniques. J Chromatogr 273:43-66.

Lindgren JÅ, Hökfelt T, Dahlén S-E, Patrono C, Samuelsson B (1984) Leukotrienes in the rat central nervous system. Proc Natl Acad Sci USA 81:6212-6216.

Lorén I, Emson PC, Fahrenkrug J, Björklund A, Alumets J, HŚkanson R, Sundler F (1976) Distribution of vasoactive intestinal polypeptide in the rat and the mouse brain. Neuroscience 4:1953-1976.

Mackie K, Devane WA, Hille B (1993) Anandamide, an endogenous cannabinoid, inhibits calcium currents as a partial agonist in N18 neuroblastoma cells. Mol Pharmacol 44:498-503.

Matsuda LA, Bonner TI, Lolait SJ (1993) Localization of cannabinoid receptor mRNA in rat brain. J Comp Neurol 327:535-550.

Miyamoto T, Lindgren JÅ, Samuelsson B (1987) Isolation and identification of lipoxygenase products from rat central nervous system. Biochim Biophys Acta 922:372-378.

Murphy RC (1993) Triacylglycerols, diacylglycerols, and monoacylglycerols. In: Handbook of lipid research. Mass spectrometry of lipids (Snyder F, ed), pp 189-211. New York: Plenum.

Natarajan V, Reddy PV, Schmid PC, Schmid HHO (1981) On the biosynthesis and metabolism of $N$-acylethanolamine phospholipids in infarcted dog heart. Biochim Biophys Acta 664:445-448. 
Natarajan V, Schmid PC, Schmid HHO (1986) $N$-acylethanolamine phospholipid metabolism in normal and ischemic rat brain. Biochim Biophys Acta 878:32-41.

Reddy PV, Natarajan V, Schmid PC, Schmid HHO (1983) $N$-acylation of dog heart ethanolamine phospholipids by transacylase activity. Biochim Biophys Acta 750:472-480.

Romero J, De Miguel R, García-Palomero E, Fernandez-Ruiz JJ, Ramos JA (1995) Time-course of the effects of anandamide, the putative endogenous cannabinoid receptor ligand, on extrapyramidal function. Brain Res 694:223-232.

Schmid HHO, Schmid PC, Natarajan V (1990) $N$-acylated glycerophospholipids and their derivatives. Prog Lipid Res 29:1-43.

Schmid HHO, Schmid PC, Natarajan V (1996a) The $N$-acylationphosphodiesterase pathway and cell signalling. Chem Phys Lipids 80:133-142.

Schmid PC, Zuzarte-Augustin ML, Schmid HHO (1985) Properties of rat liver $N$-acylethanolamine amidohydrolase. J Biol Chem 260: $14145-14149$.

Schmid PC, Krebsbach RJ, Perry SR, Dettmer TM, Maasson JL, Schmid HHO (1995) Occurrence and postmortem generation of anandamide and other long-chain $N$-acylethanolamines in mammalian brain. FEBS Lett 375:117-120.

Schmid PC, Krebsbach RJ, Perry SR, Dettmer TM, Maasson JL, Schmid HHO (1996b) Corrigendum to: Occurrence and postmortem generation of anandamide and other long-chain $N$-acylethanolamines in mammalian brain. FEBS Lett 385:125.

Shen M, Piser TM, Seybold VS, Thayer SA (1996) Cannabinoid receptor agonists inhibit glutamatergic synaptic transmission in rat hippocampal cultures. J Neurosci 16:4322-4334.

Shetty HU, Smith QR, Washizaki K, Rapoport SI, Purdon AD (1996) Identification of two molecular species of rat brain phosphatidylcholine that rapidly incorporate and turn over arachidonic acid in vivo. J Neurochem 67:1702-1710.

Skaper SD, Buriani A, Dal Toso R, Petrelli L, Romanello S, Facci L, Leon A (1996) The ALIAmide palmitoylethanolamine and cannabinoids, but not anandamide, are protective in a delayed postglutamate paradigm of excitotoxic death in cerebellar granule neurons. Proc Natl Acad Sci USA 93:3984-3989.

Smith JE, Lane JD, Shea PA, McBride WJ, Aprison MH (1975) A method for concurrent measurement of picomole quantities of acetylcholine, choline, dopamine, norepinephrine, serotonine, 5-hydroxytryptophan, 5-hydroxyindoleacetic acid, tryptophan, tyrosine, glycine, aspartate, glutamate, alanine, and $\gamma$-aminobutyric acid in single tissue samples from different areas of rat central nervous system. Anal Biochem 64:149-169.

Smith PB, Compton DR, Welch SP, Razdan RK, Mechoulam R, Martin BR (1994) The pharmacological activity of anandamide, a putative endogenous cannabinoid, in mice. J Pharmacol Exp Ther 270:219-227.

Sugiura T, Kondo S, Sukagawa A, Tonegawa T, Nakane S, Yamashita A, Waku K (1996a) Enzymatic synthesis of anandamide, an endogenous cannabinoid receptor ligand, through $\mathrm{N}$-acylphosphatidylethanolamine pathway in testis: involvement of $\mathrm{Ca}^{2+}$-dependent transacylase and phosphodiesterase activities. Biochem Biophys Res Commun 218:113-117.

Sugiura T, Kondo S, Sukagawa A, Tonegawa T, Nakane S, Yamashita A, Ishima Y, Waku K (1996b) Transacylase-mediated and phosphodiesterase-mediated synthesis of $N$-arachidonoylethanolamine, an endogenous cannabinoid-receptor ligand in rat brain microsomes. Comparison with synthesis from free arachidonic acid and ethanolamine. Eur J Biochem 240:53-62.

Takahashi T, Otsuka M (1975) Regional distribution of substance P in the spinal cord and nerve roots of the cat and the effect of dorsal root section. Brain Res 87:1-11.

Tang W, Sun GY (1985) Effects of ischemia on free fatty acids and diacylglycerols in developing rat brain. Int $\mathrm{J}$ Dev Neurosci 3:51-56.

Ueda N, Kurahashi Y, Yamamoto S, Tokunaga T (1995) Partial purification and characterization of the porcine brain enzyme hydrolyzing and synthesizing anandamide. J Biol Chem 270:23823-23827.

Venance L, Piomelli D, Glowinski J, Giaume C (1995) Inhibition by anandamide of gap junctions and intercellular calcium signalling in striatal astrocytes. Nature 376:590-593.

Vogel Z, Barg J, Levy R, Saya D, Heldman E, Mechoulam R (1993) Anandamide, a brain endogenous compound, interacts specifically with cannabinoid receptors and inhibits adenylate cyclase. J Neurochem 61:352-355.

Wood R, Snyder F (1969) Tumor lipids: metabolic relationships derived from structural analyses of acyl, alkyl, and alk-1-enyl moieties of neutral glycerides and phosphoglycerides. Arch Biochem Biophys 131:478-494. 